\title{
SCIENTIFIC REPORTS

\section{OPEN Prognostic implications of EGFR protein expression in sporadic colorectal tumors: Correlation with copy number status, mRNA levels and miRNA regulation}

\author{
Sofía del Carmen ${ }^{1}{ }^{1}$, Luís Antonio Corchete ${ }^{2}{ }^{2}$, Ruth Gervas ${ }^{1}$, Alba Rodriguez ${ }^{1}$, María Garcia ${ }^{3}$, \\ José Antonio Álcazar ${ }^{4}$, Jacinto García ${ }^{4}$, Oscar Bengoechea ${ }^{1}$, Luis Muñoz-Bellvis ${ }^{4}{ }^{4,5}$, \\ José María Sayagués $\mathbb{B}^{1,5^{*}} \& \operatorname{Mar}^{A b a d^{1,5^{*}}}$
}

Sporadic colorectal cancer (sCRC) is the third most frequent cancer worldwide and the second most common cause of cancer-related deaths (mainly due metastatic dissemination). We investigated the immunohistochemical expression of frequently altered proteins in primary tumors from 51 patients (25 liver metastatic and 26 non-metastatic cases) with a median 103 months follow-up (103 months). We evaluated EGFR copy number (using SNP arrays and FISH) and its expression and regulation (by mRNA and miRNA arrays). We found differences between metastatic and non-metastatic sCRCs for $\operatorname{MLH1}(p=0.05)$, PMS2 $(p=0.02), \operatorname{CEA}(p<0.001)$ and EGFR $(p<0.001)$ expression. EGFR expression was associated with lymph node metastases $(p=0.001)$, liver metastases at diagnosis $(p<0.001)$, and advanced stage $(p<0.001)$. There were associations between EGFR expression-, EGFR gene copy number- and EGFR mRNA levels. We found potential interactions of two miRNAs targeting EGFR expression, (miR-134 and miR-4328, in non-metastatic and metastatic tumors, respectively). EGFR expression was associated with a worse outcome $(p=0.005)$. Multivariate analysis of prognostic factors for overall survival identified that, the expression of EGFR expression $(p=0.047)$ and pTNM stage $(p<0.001)$ predicted an adverse outcome. EGFR expression could be regulated by amplification or polysomies (in metastatic tumors), or miRNAs (miRNA-134, in non-metastatic tumors). EGFR expression in SCRC appears to be related to metastases and poor outcome.

Sporadic colorectal cancer (sCRC) is the third most common cancer diagnosed worldwide and the second most frequent cause of cancer-related mortality ${ }^{1,2}$. Around 300,000 new cases of sCRC are reported annually and approximately $67 \%$ of these patients die from complications related to sCRC. Metastatic dissemination of the primary tumor, mostly liver metastasis, is the main cause of death of sCRC patients ${ }^{3}$. It is widely believed that the genetic and biological markers associated with the ability of sCRC to invade distant tissues are already present within the primary tumor cells $s^{4,5}$. Determining the markers that would help identify patients at risk of harboring or developing metastases could significantly facilitate development of new strategies for diagnosingand managing the disease.

We and others researchers have demonstrated that metastatic sCRC-specific genomic alterations, e.g., del(17p) and $\operatorname{del}(22 \mathrm{q})$, are common to primary tumors and their paired liver metastatic samples ${ }^{5-8}$, but are absent from non-metastatic sCRC tumors6. Notably, such genomic alterations of sCRC are strongly associated with unique gene expression profiles (GEPs) ${ }^{9}$.

${ }^{1}$ Department of Pathology and IBSAL, University Hospital of Salamanca, Salamanca, Spain. ${ }^{2}$ Cancer Research Center and Hematology Service (University Hospital of Salamanca), Salamanca, Spain. ${ }^{3}$ Department of Oncology, University Hospital of Salamanca, Salamanca, Spain. ${ }^{4}$ General and Gastrointestinal Surgery Service, University Hospital of Salamanca, Salamanca, Spain. ${ }^{5}$ These authors jointly supervised this work: Luis Muñoz-Bellvis, José María Sayagués and MarAbad. *email: ppmari@usal.es; marabad@usal.es 
Despite the exceptional utility of genomic methods in the discovery phase of experimentation, their use is limited in most hospitals because they are expensive techniques and difficult to apply in paraffin-embedded material. For these reasons, in practice, most routine diagnoses are performed using immunohistochemistry (IHC) techniques. These drawbacks hinder the clinical implementation of novel biomarkers of disease. In this context, IHC is highly valuable for biomarker validation for several reasons: (i) it enables biomarker expression to be directly visualized in histologically important regions of the tissue; (ii) clinical laboratories usually carry out IHC on formalin-fixed, paraffin-embedded tissue sections that have been processed by standard methods, potentially yielding hundreds of millions of specimens for study ${ }^{10}$; and (iii) validated IHC assays may be incorporated with ease into clinical practice.

Nevertheless, the development of miRNA technology and deep-sequencing techniques has provided tools for the detection and discovery of regulatory RNA molecules ${ }^{11}$. Several miRNA registry databases (miRDB v21, TargetScan 7.2, miRWalk 3, and miRTarBase 7.0) feature details of more than 2000 human miRNA genes, of which 134 were predicted to be potential regulators of EGFR expression. In this study, we searched the miRDB v21 database (http://www.mirdb.org) for candidate miRNAs that regulate EGFR expression, and examined whether the predicted miRNA regulators of EGFR displayed expression levels that were inversely correlated with expression levels of the EGFR gene. We identified EGFR as a potential target of miRNA-134 and miRNA-4328, for non-metastatic and metastatic tumors, respectively.

In the present study, we used IHC techniques to investigate the prognostic value of the expression of the proteins most commonly altered in the primary colorectal carcinomas of 51 sCRC patients ( 25 liver metastatic and 26 non-metastatic cases) with a long median follow-up. We also analyzed the expression and regulation of the EGFR gene by mRNA and miRNA genes using high-throughput arrays. Copy number alteration (CNA) of the EGFR gene was examined using $500 \mathrm{~K}$ SNP arrays and FISH techniques. Overall, our study revealed that EGFR protein expression and copy number are closely related and that EGFR expression, as shown by IHC, is an independent prognostic factor of overall survival (OS) in sCRC patients.

\section{Results}

Immunohistochemistry. All tumors were positive for CK20 and CDX2, confirming their enteric origin. For most primary antibodies analyzed, sCRC with liver metastases and non-metastatic tumors had similar expression profiles, including similar ( $p>0.05$ ) levels of expression of MSH2, MSH6, c-Myc, Her2, p53, $\beta$-catenin, and Ki-67 antibodies (Table 1). The only statistically significant differences identified between liver metastatic and non-metastatic sCRCs were those involving antibodies MLH1 $(p=0.05)$, PMS2 $(p=0.02)$, CEA $(p<0.001)$ and EGFR $(p<0.001)$. All cases showing loss of MLH1 (20\% of cases) and PMS2 (25\%) expression, and absence of CEA expression (22\% of cases) were non-metastatic tumors; most liver metastatic tumors had a positive value of EGFR membranous expression ( $79 \% v s .38 \%$ of non-metastatic cases). It should be noted that none of the non-metastatic tumors showed $\geq 35 \%$ positivity for EGFR antibody (Table 1 ).

Association between the immunohistochemical profile of SCRC tumors and other features of the disease. Expression of EGFR $>35 \%$ was associated with the presence of lymph node metastases $(p=0.001)$, liver metastases at diagnosis $(p<0.001)$, advanced stages of the disease $(p<0.001)$ and KRAS mutations $(p=0.001)$. In contrast, $\beta$-catenin expression was significantly associated with microsatellite instability $(p=0.007)$ and NRAS mutations ( $p=0.01$ ). In turn, patients who displayed moderate or intense positivity for CEA antibody were more frequently associated with localization in the rectum $(p=0.03)$, advanced stages (stage IV; $p=0.007)$, presence of lymph node metastases $(p=0.01)$, liver metastases $(p=0.003)$ and $B R A F$ mutations $(p=0.008)$. As shown in Table 2, c-Myc expression was significantly associated with advanced stages (stage IV; $p=0.03$ ), while patients showing Ki-67 expression were significantly more likely to exhibit microsatellite instability $(p=0.03)$ and BRAF mutation $(p=0.04)$ than those without such expression.

Impact of immunohistochemical profile on patient overall survival. EGFR expression was associated with a significantly worse outcome ( $p=0.005$; Fig. 1 and Table 3$)$. Advanced TNM stage $(p<0.001)$ and CEA serum levels greater than $5 \mathrm{ng} / \mathrm{ml}(p=0.008)$ were also associated with an adverse impact on patient OS (Fig. 1).

Multivariate analysis of the prognostic factors for OS revealed two variables that independently predicted an adverse outcome: EGFR expression ( $p=0.047)$ and pTNM stage $(p<0.001)$ (Table 3$)$.

EGFR protein expression and copy number. There was a significant association between EGFR IHC positivity, EGFR gene copy number, as determined by FISH, and SNP arrays and GEP, detected by oligonucleotide arrays, between metastatic and non-metastatic CRC cases (Fig. 2) and the whole series (Table 4 and Fig. 3). Most tumors with a low level of EGFR IHC expression $(<35 \%)$ were disomic ( $75 \%$ of cases, as revealed by FISH), had a normal profile (68\% of cases, demonstrated by SNP arrays) and a low level of expression of EGFR mRNA determined by oligonucleotide arrays ( $<4 \log _{2}$ expression; $55 \%$ of cases), whereas all tumors with EGFR IHC overexpression $\geq 35 \%$ ) showed amplifications (57\%) or a high proportion of polysomies (43\%) with FISH, and most exhibited EGFR gains (71\%) in the SNP analysis. In addition, all tumors with a high degree of EGFR IHC positivity $(\geq 35 \%)$ were overexpressed in oligonucleotide arrays ( $>4 \log _{2}$ expression).

The coefficient of concordance (Wt) between EGFR protein expression and copy number by arrays studies was of $0.79(\mathrm{p}=0.01)$ for EGFR $\log 2$ gene expression vs. EGFR copy number (logRatio), which indicates a good agreement between both measurements

Given the immunohistochemical criteria for the expression of p53 previously established by Kaserer et al. ${ }^{12}$, we note that most patients with loss or mutation at the p53 level (18/35 cases) showed polysomies or EGRF amplification (Supplementary Table 1). 


\begin{tabular}{|c|c|c|c|c|}
\hline Marker & $\begin{array}{l}\text { Non-metastatic } \\
\text { sCRC }(n=26)\end{array}$ & $\begin{array}{l}\text { Metastatic } \\
\text { sCRC }(n=25)\end{array}$ & $p$ & $\begin{array}{l}\text { Total } \\
(\mathrm{n}=51)\end{array}$ \\
\hline \multicolumn{5}{|l|}{ MLH1 } \\
\hline Loss & $5(20 \%)$ & $0(0 \%)$ & \multirow{3}{*}{0.050} & $5(10 \%)$ \\
\hline Normal & $20(80 \%)$ & $25(100 \%)$ & & $45(90 \%)$ \\
\hline Excluded & 1 & 0 & & 1 \\
\hline \multicolumn{5}{|l|}{ PMS2 } \\
\hline Loss & $6(25 \%)$ & $0(0 \%)$ & \multirow{3}{*}{0.020} & $6(14 \%)$ \\
\hline Normal & $18(75 \%)$ & $18(100 \%)$ & & $36(86 \%)$ \\
\hline Excluded & 2 & 7 & & 9 \\
\hline \multicolumn{5}{|l|}{ MSH2 } \\
\hline Loss & $2(8 \%)$ & $0(0 \%)$ & \multirow{3}{*}{ NS } & $2(4 \%)$ \\
\hline Normal & $22(92 \%)$ & $23(100 \%)$ & & $45(96 \%)$ \\
\hline Excluded & 1 & 2 & & 3 \\
\hline \multicolumn{5}{|l|}{ MSH6 } \\
\hline Loss & $2(8 \%)$ & $0(0 \%)$ & \multirow{3}{*}{ NS } & $2(4 \%)$ \\
\hline Normal & $23(92 \%)$ & $24(100 \%)$ & & 47 (96\%) \\
\hline Excluded & 1 & 1 & & 2 \\
\hline \multicolumn{5}{|l|}{ c-Myc } \\
\hline$<10 \%$ & $2(8 \%)$ & $7(29 \%)$ & \multirow{3}{*}{ NS } & $9(19 \%)$ \\
\hline$\geq 10 \%$ & $22(92 \%)$ & $17(71 \%)$ & & $39(81 \%)$ \\
\hline Excluded & 2 & 1 & & 3 \\
\hline \multicolumn{5}{|l|}{ Her2 } \\
\hline $0 / 1+$ & $26(100 \%)$ & $23(96 \%)$ & \multirow{4}{*}{ NS } & 49 (98\%) \\
\hline $2+$ & $0(0 \%)$ & $0(0 \%)$ & & $0(0 \%)$ \\
\hline $3+$ & $0(0 \%)$ & $1(4 \%)$ & & $1(2 \%)$ \\
\hline Excluded & 0 & 1 & & 1 \\
\hline \multicolumn{5}{|l|}{ p53 } \\
\hline 0 & $6(23 \%)$ & $7(29 \%)$ & \multirow{4}{*}{ NS } & $13(26 \%)$ \\
\hline$<10 \%$ & $9(35 \%)$ & $6(35 \%)$ & & $15(30 \%)$ \\
\hline$\geq 10 \%$ & $11(42 \%)$ & $11(46 \%)$ & & $22(44 \%)$ \\
\hline Excluded & 0 & 1 & & 1 \\
\hline \multicolumn{5}{|l|}{$\beta$-catenin } \\
\hline Negative & $18(69 \%)$ & $11(46 \%)$ & \multirow{3}{*}{ NS } & $29(58 \%)$ \\
\hline Positive & $8(31 \%)$ & $13(54 \%)$ & & $21(42 \%)$ \\
\hline Excluded & 0 & 1 & & 1 \\
\hline \multicolumn{5}{|l|}{ CEA } \\
\hline Negative & $11(22 \%)$ & $0(0 \%)$ & \multirow{2}{*}{$<0.001$} & $11(22 \%)$ \\
\hline Positive & $15(88 \%)$ & $24(100 \%)$ & & $39(78 \%)$ \\
\hline \multicolumn{5}{|l|}{ EGFR } \\
\hline 0 & $16(62 \%)$ & $5(21 \%)$ & \multirow{5}{*}{$<0.001$} & $21(42 \%)$ \\
\hline $1-10 \%$ & $4(15 \%)$ & $1(4 \%)$ & & $5(10 \%)$ \\
\hline $10-35 \%$ & $6(23 \%)$ & $4(17 \%)$ & & $10(20 \%)$ \\
\hline$>35 \%$ & 0 & $14(58 \%)$ & & $14(28 \%)$ \\
\hline Excluded & 0 & 1 & & 1 \\
\hline \multicolumn{5}{|l|}{ Ki-67 } \\
\hline$<50 \%$ & $15(58 \%)$ & $19(83 \%)$ & NS & $34(69 \%)$ \\
\hline$\geq 50 \%$ & $11(42 \%)$ & $4(17 \%)$ & & $15(31 \%)$ \\
\hline Excluded & 0 & 2 & & 2 \\
\hline
\end{tabular}

Table 1. Immunohistochemical expression in patients with metastatic $(n=25)$ and non-metastatic $(n=26)$ sporadic colorectal cancer (sCRC) at diagnosis. Results expressed as number of cases (percentage); CEA: carcinoembryogenic antigen; NS: no statistically significant differences found between groups ( $p>0.05)$. Cases excluded due to technical problems were not considered in the statistical analysis.

miRNA genes potentially regulate EGFR gene expression. In order to determine the impact of the miRNAs on EGFR gene expression in sCRC tumors, 134 candidate miRNAs targeting EGFR expression predicted from the miRDB database were combined to investigate possible correlations between miRNAs and the EGFR gene transcript in metastatic and non-metastatic tumors. Evaluation of each potential miRNA-mRNA pair targeting EGFR genes identified possible interactions for two negatively correlated (absolute $\mathrm{R}^{2} \geq 0.71 ; p<0.0001$ ) 


\begin{tabular}{|c|c|c|c|c|c|c|c|c|c|c|c|c|c|c|c|}
\hline \multirow[b]{2}{*}{ Variable } & \multicolumn{2}{|l|}{ EGFR } & \multirow[b]{2}{*}{$p$} & \multicolumn{2}{|c|}{$\beta$-catenin } & \multirow[b]{2}{*}{$p$} & \multicolumn{2}{|l|}{ CEA } & \multirow[b]{2}{*}{$p$} & \multicolumn{2}{|l|}{ c-Myc } & \multirow[b]{2}{*}{$p$} & \multicolumn{2}{|l|}{ Ki-67 } & \multirow[b]{2}{*}{$p$} \\
\hline & $<35 \%$ & $\geq 35 \%$ & & - & + & & - & + & & $<10 \%$ & $\geq 10 \%$ & & $<50 \%$ & $\geq 50 \%$ & \\
\hline \multicolumn{16}{|l|}{ Age (years) } \\
\hline$<72$ & $21(78)$ & $6(22)$ & NS & $15(55)$ & $12(45)$ & NS & $5(19)$ & $22(81)$ & NS & $6(22)$ & $21(78)$ & NS & $20(74)$ & $7(26)$ & \multirow{2}{*}{ NS } \\
\hline$\geq 72$ & $15(65)$ & $8(35)$ & & $14(61)$ & $9(39)$ & & $6(26)$ & $17(74)$ & & $3(17)$ & $18(83)$ & & $15(65)$ & $8(35)$ & \\
\hline \multicolumn{16}{|l|}{ Gender } \\
\hline Male & $25(68)$ & $12(32)$ & NS & $23(62)$ & $14(38)$ & NS & $9(24)$ & $28(76)$ & NS & $7(19)$ & $29(81)$ & NS & $24(65)$ & $13(35)$ & \multirow{2}{*}{ NS } \\
\hline Female & $11(85)$ & $2(15)$ & & $6(46)$ & $7(54)$ & & $2(15)$ & $11(85)$ & & $2(17)$ & $10(83)$ & & $11(85)$ & $2(15)$ & \\
\hline \multicolumn{16}{|l|}{ Site of primary tumor } \\
\hline Colon & $28(76)$ & $9(24)$ & NS & $22(59)$ & $15(41)$ & NS & $11(30)$ & $26(70)$ & 0.030 & $5(14)$ & $31(86)$ & NS & $25(68)$ & $12(32)$ & \multirow{2}{*}{ NS } \\
\hline Rectum & $8(62)$ & $5(38)$ & & $7(46)$ & $6(54)$ & & $0(0)$ & $13(100)$ & & $4(33)$ & $8(67)$ & & $10(77)$ & $3(23)$ & \\
\hline \multicolumn{16}{|l|}{ Histopathological grade } \\
\hline Well differentiated & $24(71)$ & $10(39)$ & & $20(59)$ & $14(41)$ & & $7(21)$ & $27(79)$ & & $7(21)$ & $26(79)$ & & $21(62)$ & $13(38)$ & \multirow{3}{*}{ NS } \\
\hline Moderately differentiated & $11(79)$ & $3(21)$ & NS & $8(57)$ & $6(43)$ & NS & $4(29)$ & $10(71)$ & NS & $2(14)$ & $12(86)$ & NS & $12(86)$ & $2(14)$ & \\
\hline Poorly differentiated & $1(50)$ & $1(50)$ & & $1(50)$ & $1(50)$ & & $0(0)$ & $2(100)$ & & $0(0)$ & $1(100)$ & & $2(100)$ & $0(0)$ & \\
\hline pT stage & & & & & & & & & & & & & & & \\
\hline $\mathrm{T} 1-\mathrm{T} 2$ & $8(100)$ & 0 & NS & $3(38)$ & $5(62)$ & NS & $3(38)$ & $5(62)$ & 0.007 & $0(0)$ & $8(100)$ & NS & $5(62)$ & $3(38)$ & NS \\
\hline T3-T4 & $28(67)$ & $14(33)$ & & $16(38)$ & $26(62)$ & & $8(19)$ & $34(81)$ & & $9(22)$ & $31(88)$ & & $30(71)$ & $12(29)$ & NS \\
\hline Lymph node involvement & & & & & & & & & & & & & & & \\
\hline No & $30(86)$ & $5(14)$ & 0.001 & $21(62)$ & $13(38)$ & NS & $11(44)$ & $24(56)$ & 0.010 & $5(15)$ & $28(85)$ & NS & $24(69)$ & $11(31)$ & NS \\
\hline $\mathrm{N} 1 / \mathrm{N} 2$ & $6(40)$ & $9(60)$ & & $8(50)$ & $8(50)$ & & $0(0)$ & $15(100)$ & & $4(27)$ & $11(73)$ & & $11(73)$ & $4(27)$ & NS \\
\hline Liver metastases at diagne & & & & & & & & & & & & & & & \\
\hline No & $29(94)$ & $2(6)$ & $<0.001$ & $19(63)$ & $11(37)$ & NS & $11(35)$ & $20(65)$ & 0.003 & $3(10)$ & $26(90)$ & NS & $19(61)$ & $12(39)$ & NS \\
\hline Yes & $7(37)$ & $12(63)$ & & $10(50)$ & $10(50)$ & & $0(0)$ & $19(100)$ & & $6(32)$ & $13(68)$ & & $6(31)$ & $13(69)$ & NS \\
\hline pTNM stage at diagnosis & & & & & & & & & & & & & & & \\
\hline I & $7(100)$ & 0 & & $2(29)$ & $5(71)$ & & $3(43)$ & $4(57)$ & & $0(0)$ & $7(100)$ & & $4(57)$ & $3(43)$ & \\
\hline II & $19(95)$ & $1(5)$ & $<0.001$ & $15(79)$ & $4(21)$ & NS & $6(30)$ & $14(70)$ & 0.007 & $2(11)$ & $16(89)$ & 0.030 & $12(30)$ & $18(70)$ & NS \\
\hline III & $3(75)$ & $1(25)$ & & $2(50)$ & $2(50)$ & & $2(50)$ & $2(50)$ & & $1(25)$ & $3(75)$ & & $3(75)$ & $1(25)$ & NS \\
\hline IV & $7(37)$ & $12(63)$ & & $10(50)$ & $10(50)$ & & $0(0)$ & $19(100)$ & & $6(31)$ & $13(69)$ & & $16(84)$ & $3(16)$ & \\
\hline Tumor size & & & & & & & & & & & & & & & \\
\hline$<4 \mathrm{~cm}$ & $8(80)$ & $2(20)$ & NS & $5(50)$ & $5(50)$ & NS & $0(0)$ & $10(100)$ & NS & $2(20)$ & $8(80)$ & NS & $9(90)$ & $1(10)$ & NS \\
\hline$\geq 4 \mathrm{~cm}$ & $28(70)$ & $12(30)$ & & $24(60)$ & $16(40)$ & & $11(28)$ & $29(72)$ & & $7(18)$ & $31(82)$ & & $26(65)$ & $14(35)$ & NS \\
\hline Microsatellite instability & & & & & & & & & & & & & & & \\
\hline No & $27(66)$ & $14(34)$ & NS & $20(49)$ & $21(51)$ & 0.007 & $4(10)$ & $37(90)$ & $<0.001$ & $9(23)$ & $30(77)$ & NS & $32(78)$ & $9(22)$ & 0.030 \\
\hline Yes & $8(100)$ & 0 & & $8(100)$ & $0(0)$ & & $8(100)$ & $0(0)$ & & $0(0)$ & $8(100)$ & & $3(37)$ & $5(63)$ & 0.000 \\
\hline KRAS mutation & & & & & & & & & & & & & & & \\
\hline No & $35(78)$ & $10(22)$ & 0.001 & $26(58)$ & $19(42)$ & NS & $11(24)$ & $34(76)$ & NS & $7(16)$ & $36(84)$ & NS & $31(69)$ & $14(31)$ & NS \\
\hline Yes & 0 & $4(100)$ & & $3(75)$ & $1(25)$ & & $0(0)$ & $4(100)$ & & $2(50)$ & $2(50)$ & & $3(75)$ & $1(25)$ & No \\
\hline NRAS mutation & & & & & & & & & & & & & & & \\
\hline No & $33(75)$ & $11(25)$ & NS & $18(53)$ & $16(47)$ & 0.010 & $10(23)$ & $34(77)$ & NS & $8(19)$ & $34(81)$ & NS & $30(68)$ & $14(32)$ & NS \\
\hline Yes & $2(50)$ & $2(50)$ & & $0(0)$ & $4(100)$ & & $1(25)$ & $3(75)$ & & $0(0)$ & $4(100)$ & & $3(75)$ & $1(25)$ & No \\
\hline BRAF mutation & & & & & & & & & & & & & & & \\
\hline No & $31(89)$ & $4(11)$ & NS & $26(58)$ & $19(42)$ & NS & $8(18)$ & $37(82)$ & \begin{tabular}{|l|}
0.008 \\
\end{tabular} & $8(20)$ & $31(80)$ & NS & $33(73)$ & $12(28)$ & 0040 \\
\hline Yes & $4(100)$ & 0 & & $1(25)$ & $3(75)$ & & $3(75)$ & $1(25)$ & & $1(25)$ & $3(75)$ & & $1(25)$ & $3(75)$ & 0.040 \\
\hline
\end{tabular}

Table 2. Expression of EGFR, $\beta$-catenin, CEA, c-Myc and Ki-67 antibodies and their association with other clinical, biological, histopathological and genetic features of sporadic colorectal cancer patients $(n=51)$. Results expressed as number of cases (percentage); CEA: carcinoembryogenic antigen; NS: no statistically significant differences found between groups $(\mathrm{p}>0.05)$.

pairs of miRNA-mRNA genes. Using available miRNA target prediction algorithms and databases indicated that, such interactions corresponded to only two predictable interactions for the inversely correlated miRNA-mRNA pair (Table 5), miR-134 and miR-4328, in non-metastatic and metastatic tumors, respectively.

Area under the receiver operating characteristic curve (AUROC) from the generalized linear model (GLM) reached a value of 0.70 considering a model with the miR-134 and miR-4328, that is, our GLM model has a chance of $70 \%$ of distinguishing between metastatic and non-metastatic patients based on the expression of those two microRNAs. Other machine learning methods used for this purpose, such as SVM (0.58), KNN (0.58) and RF (0.46), showed lower values of AUCROC indicating a weaker discriminating power. Conversely, the hierarchical 


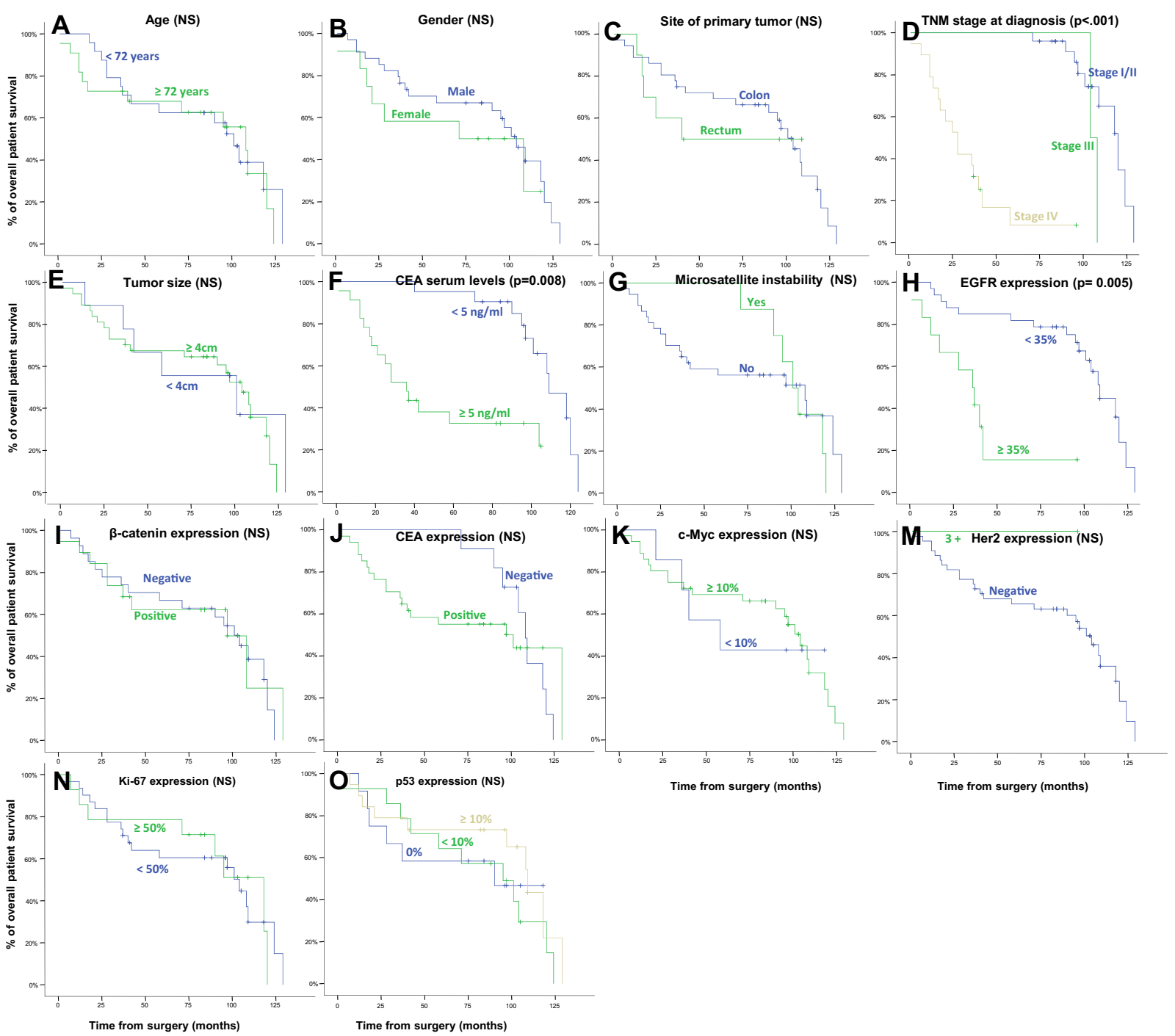

Figure 1. Clinical, biological and immunohistochemical markers of sCRC patients showing the impact on overall survival in the univariate analysis: (A) Age, $(\mathbf{B})$ gender, $(\mathbf{C})$ site of primary tumor, (D) TNM stage at diagnosis, (E) tumor size, (F) carcinoembryonic antigen (CEA) serum levels, (G) microsatellite instability, (H) EGFR expression, (I) $\beta$-catenin expression, (J) CEA expression, (K) c-Myc expression, (M) Her2 expression, (N) Ki-67 expression, and (O) p53 expression.

cluster analysis based on EGFR expression regulated by 98 miRNAs present in our array (out of 134 miRNAs total candidates) was not able to discriminate among metastatic and non-metastatic tumors, as shown in Fig. 4.

Validation of the clinical impact of the EGFR gene expression levels and its correlation with CNA in an independent series of patients. In order to confirm the clinical significance of the EGFR gene expression, we investigated its prognostic impact in an independent series of colorectal cancer patients from the public GEO database $(n=32)$. Noteworthy, also in this new series, patients whose tumors with high level of expression of EGFR mRNA determined by oligonucleotide arrays ( $>8 \log _{2}$ expression; $22 \%$ of cases), were found to have an inferior clinical outcome than those harboring low levels ( $\leq 8 \log _{2}$ expression; $78 \%$ of cases). In line with our observations, these results also confirmed the existence of significant differences in the expression of the EGFR gene between non-metastatic $(n=14)$ and metastatic cases $(n=19)$. In addition, we also found a good correlation between EGFR gene expression levels and CNA (Fig. 5). These results support the observations of our dataset and confirm the prognostic impact of EGFR expression.

\section{Discussion}

Sporadic colorectal cancer (sCRC) patients who do not exhibit or develop distant metastasis can often be cured by surgical resection of the primary tumor, and the optional administration of adjuvant therapy. However, the chances of a cure are dramatically reduced when metastasis to the liver or other organs occurs. Even though we now have a much better understanding of the genetic mechanisms that control the early stages of familial ${ }^{13}$ and $\mathrm{sCRC}{ }^{14}$, the role of IHC in stratifying patient risk is still controversial ${ }^{15-23}$. In this study, we investigated the immunohistochemical profile of primary tumors from metastatic and non-metastatic sCRC patients. To avoid 


\begin{tabular}{|c|c|c|c|c|c|}
\hline & \multirow[b]{2}{*}{$\mathbf{N}$} & \multicolumn{2}{|c|}{ Univariate analysis } & \multicolumn{2}{|l|}{ Multivariate analysis } \\
\hline & & HR (95\% CI) & $p$-value & HR (95\% CI) & $p$-value \\
\hline \multicolumn{6}{|l|}{ Variable } \\
\hline \multicolumn{6}{|l|}{ Age } \\
\hline$<72$ years & $28(55 \%)$ & Ref. & \multirow{2}{*}{0.7} & & \\
\hline$\geq 72$ years & $23(45 \%)$ & $1.14(0.56-2.31)$ & & & \\
\hline \multicolumn{6}{|l|}{ Gender } \\
\hline Male & $38(76 \%)$ & Ref. & \multirow{2}{*}{0.9} & & \\
\hline Female & $13(25 \%)$ & $0.94(0.40-2.18)$ & & & \\
\hline \multicolumn{6}{|c|}{ Site of primary tumor } \\
\hline Colon & $37(73 \%)$ & Ref. & \multirow{2}{*}{0.8} & & \\
\hline Rectum & $14(27 \%)$ & $1.13(0.48-2.66)$ & & & \\
\hline \multicolumn{6}{|c|}{ TNM stage at diagnosis } \\
\hline StageI/II & $27(53 \%)$ & Ref. & \multirow{3}{*}{$<0.001^{*}$} & Ref. & \\
\hline Stage III & $4(8 \%)$ & $2.33(1.29-4.21)$ & & $3.20(0.67-15.14)$ & 0.143 \\
\hline Stage IV & $19(39 \%)$ & $2.17(1.60-2.94)$ & & $58.37(8.66-393.62)$ & $<0.001 *$ \\
\hline \multicolumn{6}{|l|}{ Tumor size } \\
\hline$<4 \mathrm{~cm}$ & $10(20 \%)$ & Ref. & \multirow{2}{*}{0.9} & & \\
\hline$\geq 4 \mathrm{~cm}$ & $41(80 \%)$ & $1.05(0.43-2.57)$ & & & \\
\hline \multicolumn{6}{|c|}{ CEA serum levels } \\
\hline$<5 \mathrm{ng}$ & $21(48 \%)$ & Ref. & \multirow{2}{*}{$0.008^{*}$} & Ref. & 0.188 \\
\hline$\geq 5 \mathrm{ng}$ & $23(52 \%)$ & $2.81(1.28-6.16)$ & & $0.38(0.09-1.61)$ & \\
\hline \multicolumn{6}{|c|}{ Microsatellite instability } \\
\hline No & $42(84 \%)$ & Ref. & \multirow{2}{*}{0.8} & & \\
\hline Yes & $8(16 \%)$ & $1.12(0.48-2.62)$ & & & \\
\hline \multicolumn{6}{|l|}{ EGFR } \\
\hline$<35 \%$ & $36(73 \%)$ & Ref. & \multirow{2}{*}{$0.005^{*}$} & Ref. & \multirow{2}{*}{$0.044^{*}$} \\
\hline$\geq 35 \%$ & $13(27 \%)$ & $3.15(1.36-7.33)$ & & $0.31(0.10-0.97)$ & \\
\hline \multicolumn{6}{|l|}{$\beta$-catenin } \\
\hline Negative & $29(58 \%)$ & Ref. & \multirow{2}{*}{0.6} & & \\
\hline Positive & $21(42 \%)$ & $0.82(0.39-1.72)$ & & & \\
\hline CEA & & & & & \\
\hline Negative & $11(22 \%)$ & Ref. & 1 & & \\
\hline Positive & $39(78 \%)$ & $0.99(0.45-2.16)$ & 1 & & \\
\hline c-Myc & & & & & \\
\hline$<10 \%$ & $9(19 \%)$ & Ref. & 06 & & \\
\hline$\geq 10 \%$ & $39(81 \%)$ & $0.80(0.32-1.96)$ & 0.6 & & \\
\hline Her2 & & & & & \\
\hline Negative & $49(98 \%)$ & NA & NA & & \\
\hline $3+$ & $1(2 \%)$ & NA & NA & & \\
\hline Ki-67 & & & & & \\
\hline$<50 \%$ & $34(69 \%)$ & Ref. & & & \\
\hline$\geq 50 \%$ & $15(31 \%)$ & $1.00(0.45-2.20)$ & 1 & & \\
\hline p53 & & & & & \\
\hline 0 & $13(26 \%)$ & Ref. & & & \\
\hline$<10 \%$ & $15(30 \%)$ & $1.36(0.53-3.48)$ & 0.7 & & \\
\hline$\geq 10 \%$ & $22(44 \%)$ & $0.99(0.61-1.59)$ & & & \\
\hline
\end{tabular}

Table 3. Clinical, biological and immunohistochemical characteristics of sporadic colorectal cancer patients $(\mathrm{n}=50)$ and their association with overall survival. Results expressed as number of cases (percentage). HR: hazard ratio. Ref.: reference group for HR calculation. *Statistically significant at $\mathrm{p}<0.05$. NA: not available, too few data elements in one group. Stats for multivariant model: Concordance $=0.803(\mathrm{se}=0.057) ; \mathrm{R}^{2}=0.495$; Likelihood ratio test $=28.67(\mathrm{p}<0.001)$; Wald test $=26.02(\mathrm{p}<0.001)$; Score test $=37.55(\mathrm{p}<0.001)$.

false-negative non-metastatic cases, only sCRCs with a relatively long follow-up (median, 146 months) were included in the non-metastatic tumor group. Similarly, only liver metastatic patients whose primary and metastatic tumors had been completely resected were classified in the metastatic patient group.

Antibodies targeting the proteins most frequently involved in $\mathrm{sCRC}^{24,25}$ were specifically applied for the immunohistochemical characterization of the two patient groups. Previous observations showing that liver metastatic and non-metastatic sCRCs ${ }^{16,26}$ share a similar pattern of protein expression, as revealed by IHC, were 

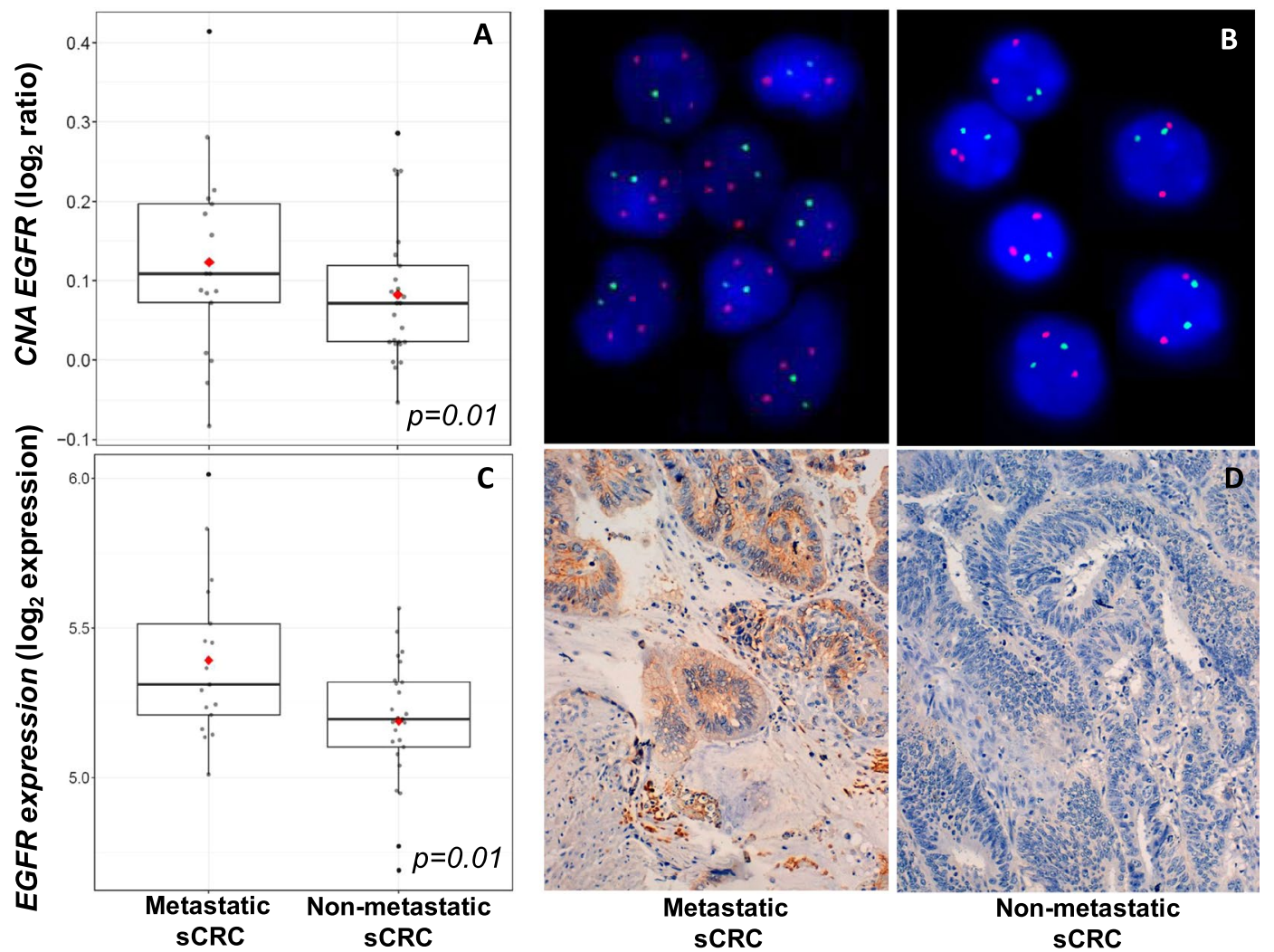

Figure 2. Copy number alterations (CNAs) and EGFR gene expression levels detected in primary tumors from patients with metastatic and non-metastatic sCRC. CNA status assessed by Affymetrix 500-K single nucleotide polymorphism (SNP)-array platform (panel A) and FISH techniques [probes for identifying chromosome 7 centromere (7p11; green spots) and EGFR gene (7p11.2; red spots)] (panel B). EGFR gene expression profile analyzed by oligonucleotide arrays (Affymetrix PrimeView Human Gene Expression microarray) (panel C) and immunostaining techniques $(20 \mathrm{x})$ (panel D). Panel (B,D) correspond to a sample of the same patient.

confirmed by our finding of similar immunohistochemical profiles in metastatic and non-metastatic liver tumors for the expression of most of the antibodies studied (e.g., high levels of c-Myc and p53, Her2 negativity, and Ki-67 expression $\leq 50 \%$ in most cases). Conversely, MLH1, PMS2, CEA and EGFR expression was markedly more common in, and in same cases exclusive to, liver metastatic tumors. Our findings imply that these four proteins may play a role in the metastasis of sCRC to the liver.

Earlier reports of immunohistochemical analyses of metastatic disease in colorectal tumors demostrated the presence of microsatellite instability (MSI) arising from the loss of DNA mismatch repair (MMR) expression in $15 \%$ of sCRC tumors ${ }^{27,28}$. Consistent with the findings of other studies, and using similar methods, we found MSI to be present in $16 \%$ of the sCRC cases studied. The MSI detection rate was also significantly higher in our non-metastatic patients than in liver metastatic cases a pattern that has been described by other groups ${ }^{28-30}$. Several studies have shown that the microsatellite profile in sCRC provides useful prognostic information ${ }^{29}$, indicating that patients with MSI neoplasms have better OS and a modified response to conventional chemotherapy ${ }^{31}$. However, the better prognosis of MSI carcinomas is not established beyond doubt; other studies have shown that these tumors behave similary, from a clinical point of view, to microsatellite-stable (MSS) carcinomas, and no clinical benefit has been observed except in stage II tumors ${ }^{32}$. There is still no definitive explanation of the prognostic advantage accruing from MSI, although intense lymphocytic infiltration, an increased rate of apoptosis, and infrequent allelic loss or mutation of TP53, DCC, KRAS and BRAF in MSI colorectal cancer are thought by some to determinate their clinical behavior ${ }^{33-35}$.

The consensus statement of the College of American Pathologists published in 1999 indicated that pathological TNM stage, extramural venous invasion, and preoperative CEA serum level are the most important category I prognostic factors ${ }^{36}$. It is well established that the preoperative CEA serum level is an important prognostic factor $^{36,37}$, whereby levels greater than $5 \mathrm{ng} / \mathrm{ml}$ are related to worse prognosis. In fact, our recent study reported highly prevalent, abnormally high CEA serum levels $(\geq 7.5 \mathrm{ng} / \mathrm{ml})$ in the great majority of primary sCRC patients who had synchronous liver metastasis ${ }^{6}$. Consistent with the findings of previous studies using IHC techniques ${ }^{23}$, we observed a significantly higher level of CEA expression in patients with metastatic tumors than in those with non-metastatic tumors. CEA is involved in cell adhesion, protecting cells from anoikis (apoptosis induced by the loss of anchoring of the cell to the extracellular matrix ${ }^{38}$, which favors the cell's metastatic potential. In addition, CEA can bind to Kupffer cells ${ }^{39}$, modulate the inflammatory response in the liver, and protect tumor cells from oxygen radicals ${ }^{40}$. In vitro studies have shown resistance of cells expressing CEA to lysis induced by activated 


\begin{tabular}{|c|c|c|c|}
\hline & \multicolumn{2}{|c|}{ EGFR IHC expression } & \multirow[b]{2}{*}{$p$} \\
\hline & $<35 \%$ & $\geq 35 \%$ & \\
\hline \multicolumn{4}{|l|}{ FISH } \\
\hline Normal & $27(75 \%)$ & 0 & \multirow{3}{*}{$<0.001$} \\
\hline Amplification & 0 & $8(57 \%)$ & \\
\hline Polysomy & $9(25 \%)$ & $6(43 \%)$ & \\
\hline \multicolumn{4}{|l|}{ SNPs } \\
\hline Normal & $21(68 \%)$ & $2(29 \%)$ & \multirow{2}{*}{0.07} \\
\hline Gain & $10(32 \%)$ & $5(71 \%)$ & \\
\hline \multicolumn{4}{|l|}{ GEP* } \\
\hline$<4$ & $17(55 \%)$ & 0 & \multirow{2}{*}{0.009} \\
\hline$\geq 4$ & $14(45 \%)$ & $7(100 \%)$ & \\
\hline
\end{tabular}

Table 4. Correlation between EGFR immunohistochemical (IHC) expression, EGFR gene copy number, determined by FISH techniques and SNP-arrays, and GEP, detected by oligonucleotide arrays, in patients with sporadic colorectal cancer at diagnosis. FISH: interphase fluorescence in situ hybridization; SNP: single nucleotide polymorphism; GEP: gene expression profile; IHC: immunohistochemistry; Results expressed as number of cases and percentage in parentheses. ${ }^{*} \log _{2}$ expression. SNPs arrays and GEP studies were performed in 38 cases due to sample restrictions

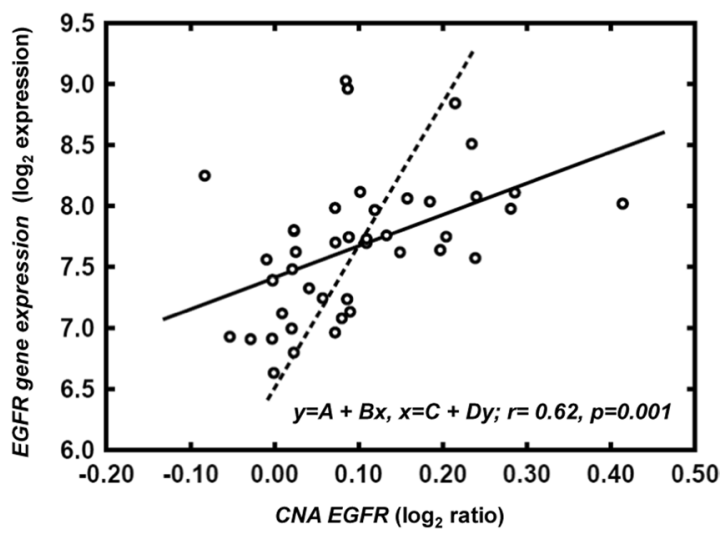

Figure 3. Correlation between EGFR gene expression using oligonucleotide arrays and CNA by SNP arrays in patients with sporadic colorectal cancer at diagnosis. The graphs show the regression lines for $\mathrm{Y}$ as a function of $\mathrm{X}$ (solid line) and for $\mathrm{X}$ as a function of $\mathrm{Y}$ (dashed line). If these regression lines are approximately perpendicular, it indicates that $\mathrm{X}$ and $\mathrm{Y}$ are not linearly correlated. The closer the lines, the greater the correlation.

killer cells (LAK cells ${ }^{41}$. These biological functions of CEA may explain why tumors with stronger expression have greater metastatic potential.

In addition to CEA expression associated with the metastatic process, we also found EGFR expression to be an independent prognostic factor of disease outcome, as previously observed ${ }^{42,43}$. Previous studies employing IHC analysis ${ }^{42,43}$ have shown an association between EGFR expression and liver metastasis in sCRC patients; here, we also found that EGFR-positive tumors had lymph node metastases and a higher TNM category at diagnosis. Similarly, Goos et al. ${ }^{44}$ reported that, in a series of 323 patients with metastatic CRC, those who strongly expressed EGFR had a worse prognosis. Other studies have found a correlation between EGFR expression and more advanced disease $\mathrm{e}^{43,45,46}$, metastatic spread ${ }^{23,47,48}$ and worse prognosis ${ }^{49}$. In addition, Du P et al. ${ }^{48}$ have suggested that EGFR is important in the angiogenesis in early tumors. EGFR is linked to colorectal carcinoma progression, and so is a widely used prognostic factor. However, other authors have reported controversial results from their IHC assessment of EGFR expression and its correlation with sCRC prognosis. Tsai et al. ${ }^{50}$ found no differences in EGFR expression between tumors of various grades and stages, or in survival, despite analyzing a large series of patients $(n=150)$. This could be because EGFR-positive cases were classified into three categories $(1+, 2+$ and $3+$ ), rather than being measured as the percentage of positive tumor cells, as we have done in the present study.

Genomic heterogeneity is a weidely acknowledged challenge in the treatment of colorectal tumors. To compare the results obtained by techniques that analyze individual cells with those from methods based on the entire genome, we extracted the DNA/RNA from the same tumor tissue analyzed in the TMAs through microdissections of the paraffin-embedded tissue. In this way, we found significant correlations between EGFR staining results, and those of oligonucleotide expression arrays, FISH analysis and SNP arrays. This is the first study in which the immunohistochemical expression of EGFR has been validated by three molecular techniques in metastatic and non-metastatic tumors. In accordance with other studies, EGFR overexpression was frequently 


\begin{tabular}{|c|c|c|c|c|}
\hline miRNA & $\mathbf{R}^{2}$ & $p$ & $\begin{array}{l}\text { Classification of } \\
\text { interaction }\end{array}$ & Source of validation/prediction \\
\hline \multicolumn{5}{|c|}{ Non-metastatic tumors } \\
\hline hsa-miR-134_st & -0.72 & $<0.001$ & Predicted & miRWalk, miRDB, MiRanda, DIANAmT \\
\hline hsa-miR-3144-3p & -0.53 & 0.006 & Predicted & miRWalk, miRDB, TargetScan \\
\hline hsa-miR-4659a-5p & -0.52 & 0.007 & Predicted & miRWalk, miRDB \\
\hline hsa-miR-133b & -0.51 & 0.009 & Predicted & miRDB \\
\hline hsa-miR-651_st & -0.47 & 0.01 & Predicted & miRDB, TargetScan \\
\hline hsa-miR-27a-star_st & -0.46 & 0.02 & Predicted & miRDB, MiRanda, TargetScan \\
\hline hsa-miR-4476 & -0.42 & 0.03 & Predicted & miRDB, miRWalk, TargetScan \\
\hline hsa-miR-155_st & -0.42 & 0.03 & Predicted & miRDB, TargetScan \\
\hline hsa-miR-1227_st & -0.42 & 0.03 & Predicted & miRDB, miRWalk, TargetScan \\
\hline hsa-miR-3126-3p & -0.42 & 0.03 & Predicted & miRDB, TargetScan \\
\hline \multicolumn{5}{|l|}{ Metastatic tumors } \\
\hline hsa-miR-4328 & -0.71 & 0.001 & Predicted & miRDB, TargetScan, MiRanda, DIANAmT \\
\hline hsa-miR-651_st & -0.64 & 0.006 & Predicted & miRDB, TargetScan, miRWalk \\
\hline hsa-miR-3616-5p & -0.63 & 0.006 & Predicted & miRDB, TargetScan \\
\hline hsa-miR-876-3p & -0.62 & 0.008 & Predicted & miRDB, miRWalk \\
\hline hsa-miR-1233_st & -0.61 & 0.01 & Predicted & miRDB, TargetScan, miRWalk \\
\hline hsa-miR-548e_st & -0.60 & 0.01 & Predicted & miRDB \\
\hline hsa-mir-302c_st & -0.59 & 0.01 & Predicted & miRDB \\
\hline hsa-mir-373_st & -0.55 & 0.02 & Predicted & miRDB, TargetScan, miRWalk \\
\hline hsa-miR-3686 & -0.55 & 0.02 & Predicted & miRDB, TargetScan, miRWalk \\
\hline hsa-miR-19a-star_st & -0.55 & 0.02 & Predicted & miRDB, TargetScan, miRWalk \\
\hline hsa-miR-646 & -0.54 & 0.03 & Predicted & miRDB, TargetScan, miRWalk \\
\hline hsa-miR-4504 & -0.53 & 0.03 & Predicted & miRDB, TargetScan \\
\hline hsa-mir-141_st & -0.52 & 0.03 & Predicted & miRDB, TargetScan, miRWalk \\
\hline hsa-miR-4659a-5p & -0.52 & 0.03 & Predicted & miRDB, TargetScan \\
\hline
\end{tabular}

Table 5. miRNA-mRNA interactions identified in non-metastatic and metastatic colorectal patients by Pearson correlation analysis of the expression signal identified for EGFR transcripts, detected by the Affymetrix PrimeView human gene expression array and the microRNA 3.0 expression array. $\mathrm{R}^{2}$ : Pearson correlation coefficient.

accompanied by gene amplification and/or a high frequency of chromosome 7 polysomies, especially in metastatic colorectal tumors, as found by other researchers ${ }^{47,51-53}$. Two reviews of the data have shown that patients with sCRC that has been diagnosed as EGFR-positive by FISH also responded to cetuximab monotherapy treatment $^{52,53}$. In fact, the dose of cetuximab that was sufficient to inhibit proliferation in mCRC cell populations with amplified numbers of EGFR copies had no effect on cell populations without EGFR amplification. Moroni $\mathrm{M}$ et al. found that eight of nine patients with objective responses who could be assessed by FISH had a higher EGFR copy number, suggesting that selection of candidates for anti-EGFR therapy may be based on EGFR gene copy number ${ }^{52}$. Our findings show that transcriptional upregulation, abnormal receptor structure secondary to genetic alterations (e.g., mutation and polymorphism) gene amplification or specific miRNA levels could be responsible for EGFR overexpression, and therefore predictors of disease prognosis ${ }^{54,55}$.

Here, we also identified miR-134 and miR-4328 as negatively regulated EGFR targets in non-metastatic and metastatic tumors, respectively. Previous studies have confirmed that both miRNAs have important roles in the progression of sCRC. These studies of the EGFR-miRNA regulation network draw attention to the possibilities of using miRNA-based therapy to target EGFR, in addition to employed tyrosine kinase inhibitors and classical monoclonal antibodies for EGFR-targeted therapies,. miRNA-134 has important roles in cancer, such as regulating migration ${ }^{56}$, invasion ${ }^{56}$, cell proliferation ${ }^{56,57}$, and the epithelial-mesenchymal transition ${ }^{58,59}$. Qin et al.$^{60}$, using intratumoral injection of miR-134, observed a reduction in the expression of EGFR in non-small-cell lung carcinoma (NSCLC) cell lines, suggesting that the use of miR-134 could be a potential strategy for EGFR-targeted therapy. Sherien et al. ${ }^{61}$ showed that miRNA-134 is a potential tumor suppressor miRNA and could be fundamental to the suppression of colorectal cancer tumorigenesis since it is able to regulate the EGFR signaling cascade in a coordinated fashion by independently targeting EGFR and PIK3CA. In metastatic tumors, EGFR overexpression was more frequently detectedas a consequence of gene amplification or a high frequency of polysomies. Interestingly, interactions of the inversely correlated miRNA-mRNA pairs in the metastatic patient series revealed miRNA-4328 to be a possible regulator of EGFR expression. Information is available about miRNA-4328 in CRC patients; it has been previously described as an EGFR regulator in EGFR-mutated lung adenocarcinomas $^{62}$. However, further GEP and functional studies, and direct comparison of non-metastatic and metastatic tumors are needed to confirm our observations and to provide deeper insight into the role of miRNA-4328 in metastatic CRC patients. 


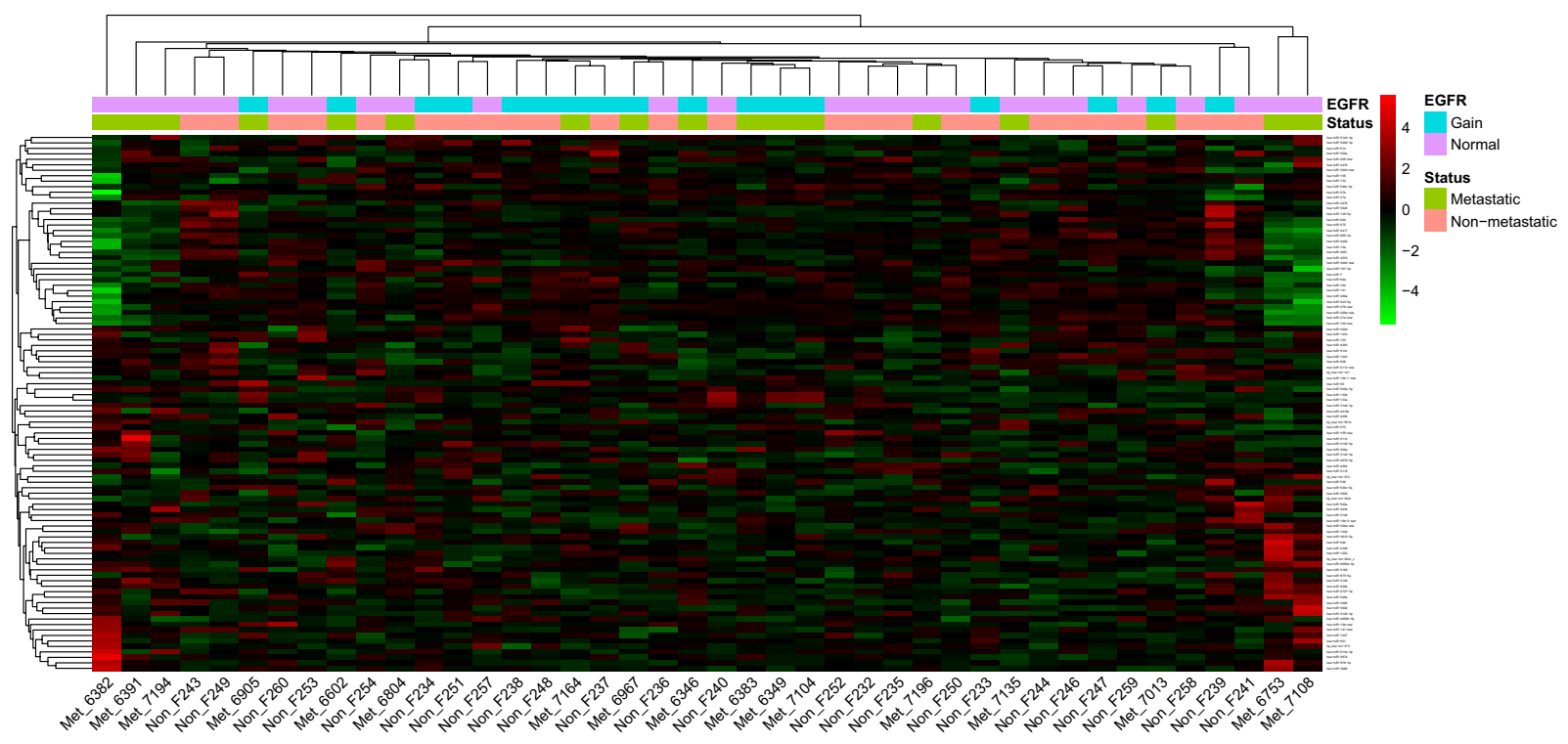

Figure 4. Hierarchical cluster analysis based on EGFR expression regulated by 98 miRNAs present in our array (out of 134 miRNAs total candidates) of the non-metastatic $(n=25)$ and metastatic cases $(n=26)$ included in the study.

In summary, in the present study, we show that EGFR protein expression and copy number are closely related. EGFR expression is an independent adverse prognostic factor of OS in sCRC patients. The expression of the EGFR gene could be regulated by amplification mechanisms or a high frequency of polysomies, as is often observed in metastatic tumors, or by miRNAs (i.e., miRNA-134) in non-metastatic tumors. We also showed that the possible involvement of EGFR expression in sCRC patients with liver metastasis is inherently related to greater metastatic potential and worse outcome, which provides additional prognostic information about the pTNM stage. Additional prospective studies, in larger series, are needed to confirm the utility of the proposed predictive model.

\section{Materials and Methods}

Approval. The study was approved by the local ethics committee of the University Hospital of Salamanca (Salamanca, España).

Accodance. All procedures performed in studies involving human participants were in accordance with the ethical standards of the institutional and/or national research committee and with the 1964 Helsinki declaration and its later amendments or comparable ethical standards.

Informed consent. Informed consent was obtained from all participants before entering the study,

Patients and samples. Tissue specimens from $51 \mathrm{sCRC}$ patients who had undergone surgical resection of primary tumor tissues between June 2000 and September 2007 in the Department of Surgery of the University Hospital of Salamanca, Salamanca, Spain, were included in the study, prior to administering any cytotoxic therapy.

In all cases, tumor were diagnosed and classified according to the criteria of the $\mathrm{AJCC}^{63}$ [12]. The median follow-up at the moment of closing the study was 103 months for the whole series (range: 1-172 months). The median follow-up for metastatic patients was 49 months (range: 1-153 months) and 146 months (range: 54-172) for non-metastatic patients. About half the patients $(n=25 ; 49 \%)$ developed liver metastases during the first 8 months after colorectal surgery $(n=16)$, or later, during follow-up $(n=9)$. The other 26 patients $(51 \%)$ were non-metastatic sCRC cases, selected on the basis of the absence of metastatic dissemination and after a minimum follow-up of 5 years. Patient clinical, laboratory and follow-up data are summarized in Table 6.

Patient characteristics. Overall, 51 patients diagnosed with sCRC at the University Hospital of Salamanca (38 males and 13 females; median age, 67 years, range: 38 to 83 years) were studied. Histologically, all cases were adenocarcinomas. By tumor grade, 35, 14 and 2 cases were classified as well, moderately and poorly differentiated carcinomas, respectively. In all cases, histopathological grade was systematically confirmed by a second, independent evaluation by another experienced pathologist. The most relevant clinical and laboratory data for each individual sCRC patient studied are summarized in Table 6.

All patients underwent complete surgical tumor resection (R0). sCRC cases with liver metastases were most frequently located in the rectum $(p=0.02)$, and tended to show a higher frequency of lymph node metastases $(p<0.001)$ and abnormally higher CEA serum levels $(p<0.001)$ than non-metastatic patients (Table 1$)$. From the prognostic point of view, sCRC with liver metastases also had a higher frequency of deaths associated with significantly shorter patient OS (median, 30 vs. 100 months, respectively; $p<0.001$ ). By contrast, no significant 

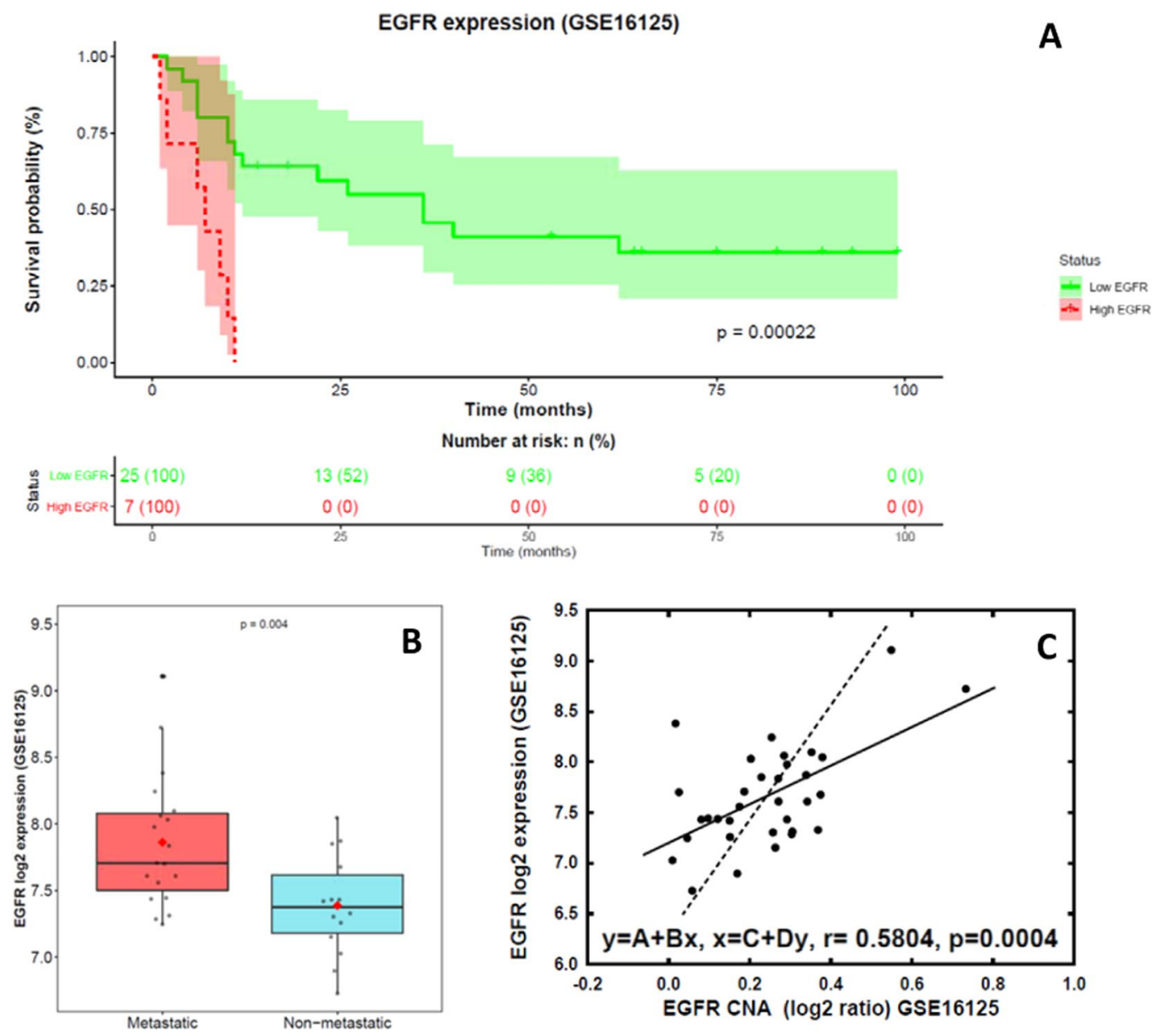

Figure 5. Validation of the impact of EGFR expression on overall survival in an independent series of sCRC patients from the GEO database $(n=32)$ : panel $(A)$, EGFR expression showing the impact on overall survival; panel (B), EGFR gene expression levels detected in primary tumors from patients with metastatic and nonmetastatic sCRC; and panel (C), correlation between EGFR gene expression using oligonucleotide arrays and CNA by SNP arrays in patients with sporadic colorectal cancer at diagnosis.

differences were found between liver metastatic and non-metastatic CRC cases with respect to patient age, gender and histological grade (Table 6).

Tissue microarray (TMA). Paraffin blocks containing formalin-fixed primary tumors were produced for all patients. For each of these, a 0.6-mm diameter core biopsy was taken from the tumor in the paraffin blocks with tissue microarray apparatus. Tissue cores of each specimen were arranged on recipient paraffin blocks and embedded. Two colon cancer TMAs were prepared using a Beecher MTA-1 Manual Tissue Microarrayer, incorporating tissue selected by a pathologist from histological sections. One TMA contained samples from metastatic tumors and the other contained non-metastatic cases. Cores of normal tissue were added and all tumor samples were included in triplicate in both TMAs (Fig. 6).

Immunohistochemistry. $\quad 4-\mu$ m-thick sections of the TMA blocks were immunohistochemically stained. Paraffin sections were deparaffinized in xylene and rehydrated in an ethanol series. Microwave-induced antigen retrieval was carried out in $0.01 \mathrm{M}$ citrate buffer, $\mathrm{pH}$ 6.0. Endogenous peroxidase activity was curtailed using $0.3 \%$ hydrogen peroxide in methanol for $15 \mathrm{~min}$. Antibodies and reagents were included automatically using the Leica BOND-III processor (A. Menarini Diagnostics, San Diego, CA), following previously published standard protocols ${ }^{64}$. Sections were counterstained with hematoxylin, dehydrated and mounted. Primary antibodies, dilutions, manufacturers,interpretations and positive controls used are specified in Supplementary Table 2. Based on a literature review, we established different cutoffs for each antibody used (c-Myc: $<10 \%, \geq 10 \%{ }^{22}$; Her2: $0 / 1+, 2+$, $3+{ }^{21}$; p53: $0,<10 \%, \geq 10 \%{ }^{12} ;$ B-catenin: $<30 \%, \geq 30 \%{ }^{25}$; CEA: no stained cells or non-specific stain, any specific cytoplasmic stain ${ }^{20,41}$; EGFR: $0,1-10 \%, 10-35 \%,>35 \%{ }^{44}$; Ki67: $<50 \%, \geq 50 \%{ }^{17,18}$.

Cases in which there was no tumor sample that could be assessed by immunohistochemical techniques (due to detachment of the tissue in fron the slide, tumor depletion, or a poor outcome from the technique) were excluded and not considered in the statistical analysis (Table 1). 


\begin{tabular}{|c|c|c|c|c|}
\hline Variable & $\begin{array}{l}\text { Non-metastatic } \\
\text { sCRC }(n=26)\end{array}$ & $\begin{array}{l}\text { Metastatic sCRC } \\
(\mathrm{n}=25)\end{array}$ & $p$ & Total $(\mathbf{n}=51)$ \\
\hline Age (years)* & $67(38-83)$ & $67(48-79)$ & NS & $67(38-83)$ \\
\hline \multicolumn{5}{|l|}{ Gender } \\
\hline Female & $7(27 \%)$ & $6(24 \%)$ & \multirow{2}{*}{ NS } & $13(25 \%)$ \\
\hline Male & $19(73 \%)$ & $19(76 \%)$ & & $38(75 \%)$ \\
\hline \multicolumn{5}{|l|}{ Site of primary tumor } \\
\hline Right colon & $9(35 \%)$ & $4(16 \%)$ & \multirow{3}{*}{0.020} & $13(26 \%)$ \\
\hline Left colon & $14(54 \%)$ & $10(40 \%)$ & & $24(47 \%)$ \\
\hline Rectum & $3(11 \%)$ & $11(44 \%)$ & & $14(27 \%)$ \\
\hline \multicolumn{5}{|l|}{ Histopathological grade } \\
\hline Well differentiated & $19(73 \%)$ & $16(64 \%)$ & & $35(69 \%)$ \\
\hline Moderately differentiated & $6(23 \%)$ & $8(32 \%)$ & \multirow{2}{*}{ NS } & $14(27 \%)$ \\
\hline Poorly differentiated & $1(4 \%)$ & $1(4 \%)$ & & $2(4 \%)$ \\
\hline \multicolumn{5}{|c|}{ Histopathological tumor classification } \\
\hline pT1 & $1(4 \%)$ & $0(0 \%)$ & \multirow{4}{*}{0.060} & $2(4 \%)$ \\
\hline pT2 & $6(23 \%)$ & $1(4 \%)$ & & $6(11 \%)$ \\
\hline pT3 & $11(42 \%)$ & $19(76 \%)$ & & $30(59 \%)$ \\
\hline pT4 & $8(31 \%)$ & $5(20 \%)$ & & $13(26 \%)$ \\
\hline \multicolumn{5}{|l|}{ Lymph node involvement } \\
\hline pN0 & $26(100 \%)$ & $9(36 \%)$ & \multirow{3}{*}{$<0.001$} & $35(69 \%)$ \\
\hline $\mathrm{pN} 1$ & $0(0 \%)$ & $11(44 \%)$ & & $11(21 \%)$ \\
\hline $\mathrm{pN} 2$ & $0(0 \%)$ & $5(20 \%)$ & & $5(10 \%)$ \\
\hline \multicolumn{5}{|l|}{ TNM stage at diagnosis } \\
\hline I & $6(23 \%)$ & $1(4 \%)$ & \multirow{7}{*}{$<0.001$} & $7(14 \%)$ \\
\hline IIA & $1(4 \%)$ & $2(8 \%)$ & & $3(6 \%)$ \\
\hline IIB & $17(65 \%)$ & $0(0 \%)$ & & $17(33 \%)$ \\
\hline IIIA & $0(0 \%)$ & $0(0 \%)$ & & $0(0 \%)$ \\
\hline IIIB & $2(8 \%)$ & $1(4 \%)$ & & $3(6 \%)$ \\
\hline IIIC & $0(0 \%)$ & $1(4 \%)$ & & $1(2 \%)$ \\
\hline IV & $0(0 \%)$ & $20(80 \%)$ & & $20(39 \%)$ \\
\hline CEA serum levels* & $4.18(0.60-17.96)$ & $269.22(0.84-1484)$ & $<0.001$ & $118.63(0.60-1484)$ \\
\hline Number of deaths** & $2(8 \%)$ & $13(72 \%)$ & $<0.001$ & $15(34 \%)$ \\
\hline OS (months)** & $99.69(71-124)$ & $31.61(7-96)$ & $<0.001$ & $71.84(7-124)$ \\
\hline
\end{tabular}

Table 6. Clinical and biological characteristics of patients with metastatic $(n=25)$ and non-metastatic $(n=26)$ sporadic colorectal cancer (sCRC) at diagnosis. Results expressed as number of cases (percentage), except * as median (range). **Survival rate calculated for 44 patients (26 non-metastatic and 18 metastatic). CEA: carcinoembryogenic antigen; OS: overall survival; NS, no statistically significant differences found between groups $(p>0.05)$.

We found no significant variability between the three tumor samples of the patient included in the TMAs.

FISH analysis. Separate FISH analyses were performed for each TMA, one containing samples from metastatic tumors and the other from non-metastatic cases. The TMA slides were preheated overnight at $60^{\circ} \mathrm{C}$, then deparaffinized in xylene and ethanol. The slides were submerged in Vysis Paraffin Pretreatment Reagent (Vysis; Downers Grove, IL) for $13 \mathrm{~min}$ at $80^{\circ} \mathrm{C}$ in a waterbath. Sections were rinsed with deionized water before treating the slides with protease solution $(250 \mathrm{mg}$ pepsin $+62.5 \mathrm{ml} 0.2 \mathrm{~N} \mathrm{HCl}, \mathrm{pH} 1.0)$ for $13 \mathrm{~min}$ at $37^{\circ} \mathrm{C}$ in a waterbath. After rinsing and air-drying, $20 \mu \mathrm{l}$ of probe was added to each TMA slide. A set of two probes (LSI-EGFR, spectrum orange; CEP-7, spectrum green) (Vysis Inc., Downers Grove, IL) was used. A coverslip was placed on each slide and sealed in place with rubber cement. Slides were then denatured for $5 \mathrm{~min}$ at $75^{\circ} \mathrm{C}$, and hybridized overnight at $37^{\circ} \mathrm{C}$ in a Hybrite thermocycler (Vysis). Slides underwent post-hybridization washing consisting of in 2 X SSC with $0.3 \% \mathrm{NP}-40$ at $73^{\circ} \mathrm{C}$ in a waterbath for $1 \mathrm{~min}$. The slides were air-dried in darkness and counterstained with $20 \mu$ l of DAPI (Sigma, St. Louis, MO). $5 \mu$ l of Vectashield (Vector Laboratories, Burlingame, CA) was used as an antifading agent. The number of hybridization spots per nuclei of $\geq 200$ cells per sample was quantified using a BX60 fluorescence microscope (Olympus, Hamburg, Germany) equipped with a $100 \times$ oil objective. EGFR gene amplification was defined as an EGFR/CEP7 ratio $\geq 2$, in accordance with the manufacturer's recommendations. In all cases it was possible to quantify at least 200 tumor nuclei. Two pathologists independently interpreted the results, and concurred completely in their observations.

Once the TMAs had been prepared, consecutive sections of paraffin-embedded tissue samples were microdissected by an experienced pathologist. DNA/RNA was extracted and isolated using a Maxwell ${ }^{\circledR} 16$ System for 


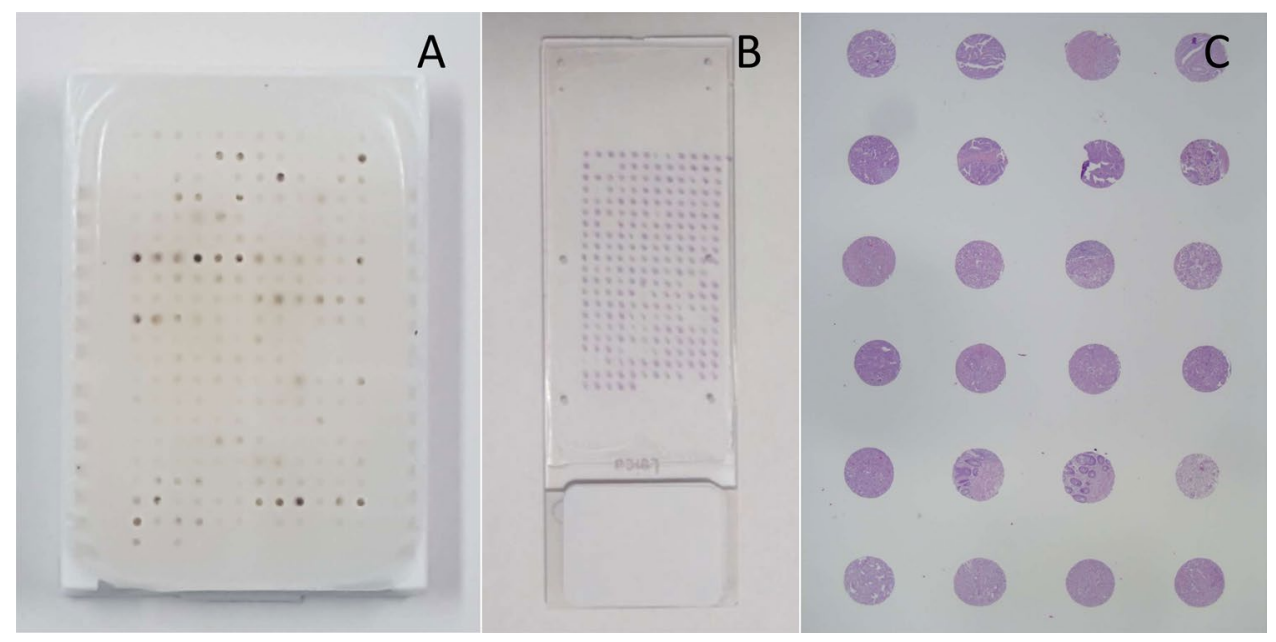

Figure 6. TMA: (A) TMA paraffin block; (B) TMA slide, hematoxylin-eosin; (C) hematoxylin-eosin panoramic view, $3-\mu \mathrm{m}$ section.

Genomic DNA/RNA Extraction (Promega, Mannheim, Germany) and quantified using a Qubit dsDNA BR and RNA assay (Invitrogen, Life Technologies, CA, USA)

Identification of copy number alterations by SNP arrays. Data from two 250-K Affymetrix SNP mapping arrays (NspI and StyI SNP arrays; Affymetrix, Santa Clara, CA) previously reported by us ${ }^{8}$ were used to analyze EGFR CNAs. The aroma.affymetrix algorithm was used, following the CRMA version 2 method in $\mathrm{R}^{65}$ ( $\mathrm{R}$ Foundation for Statistical Computing, Vienna, Austria; available at: http://www.aroma-project.org, accessed 18 March 2014). The steps taken to normalize the arrays were those described by Munoz-Bellvis et al. ${ }^{66}$. Data from the 250-K StyI and 250-K NspI arrays were then compiled in a single database. Raw copy numbers were recalculated for each group as transformed $\log _{2}$ values of the following ratios: group 1 primary tumor $=$ normal PB; group 2 primary tumor $=$ normal $\mathrm{PB}$; and group 1 primary tumor $=$ group 2 primary tumor.

The criteria used to define single-point copy number changes in the EGFR gene were based on values of $p<0.01$ for at least seven markers for each DNA segment, and smoothed values were used to assign median segment values to each probe. To identify CNAs (gains or losses), a threshold was declared based on the changes in the fluorescence intensity of sequential DNA segments for primary tumor versus $\mathrm{PB}$ ( $\log _{2}$ ratio cutoff values of $>0.09$ and $<20.09$ for gains and losses, respectively). Moderated t tests were used to identify significant differences in the mean copy number of metastatic and non-metastatic samples (FDR-corrected $p<0.05$ ).

Gene expression profile microarray studies. Data from two expression arrays, Affymetrix PrimeView Human Gene Expression and the microRNA 3.0 Expression arrays (Santa Clara, CA), previously reported by us ${ }^{67}$ were used to analyze EGFR expression. Raw GEP data were obtained from the Gene Expression Omnibus (GEO) database (accession number GSE81582). The data are based on sets of 49,395 and 5,683 probes, respectively, for the Affymetrix PrimeView Human Gene Expression microarray and the microRNA 3.0 microarray. For data analysis, raw GEP data were normalized by applying the Robust Multi-array Average (RMA) algorithm, which includes sequential background correction, intra- and inter-microarray well normalization, probe set summarization and calculation of expression signals ${ }^{68}$. Samples and the EGFR gene were classified in an unsupervised manner by multi-dimensional scaling (MDS) and hierarchical clustering analysis (HCA) based on the expression signal of each gene of each probe set, using Simfit software (http://www.simfit.org.uk/). Clustering was carried out assuming Euclidean distances and employing the linkage method group average. Genes differentially expressed (miRNA and mRNA) in tumoral and non-tumoral samples were identified by estimating the supervised two-class unpaired significance of microarray (SAM) ${ }^{69}$ based on a cutoff value of $\mathrm{q} \leq 0.01$ and an absolute $\geq 2.0$-fold change cutoff.

In addition, we have performed a concordance analysis between EGFR protein expression and copy number by arrays studies using the Kendall's (W) concordance coefficient through the DescTools R package (v. 0.99.31).

miRNA candidates acting as regulators of the EGFR gene in colorectal samples were identified by Pearson correlation analysis, which determined the significant associations between EGFR gene transcripts and deregulated miRNA in primary colorectal tumors, compared with non-tumoral colorectal tissue. The psych R-package, based on an adjusted FDR of $\leq 0.05$ was used. We analyzed 134 candidate miRNAs targeting EGFR expression predicted from the miRDB database. Each potential miRNA-mRNA interaction identified was evaluated against the TarBase 8.0 and miRWalk databases of experimentally validated miRNA interactions, and the DIANA-microT-CDS v5.0, miRWalk-database, TargetScanHuman and miRecords miRNA target prediction tools ${ }^{70,71}$.

Hierarchical dendrograms were performed in R using the gplots (v.3.0.1.2) and the pheatmap (v. 1.0.12) packages. Dendrograms were performed using the Euclidean distance as distance measure and the group average as linkage method (Fig. 4). 
A ROC analysis was included to further support the power of miR-134 and miR-4328 in discriminating the non-metastatic and metastatic tumors. Area under ROC curve (AUROC) analysis was performed using the Generalized Linear Models (GLM), Support Vector Machines (SVM), K-Nearest Neighbors (KNN) and Random Forest (RF) classification methods. Analyses were performed in R using the randomForest (v. 4.6-14), e1071 (v. 1.7-3) and caret (v. 6.0-85) packages by k-fold cross validation considering 5 folds and 1000 repeats. The optimal kernel for SVM analysis was determined using the OptimClassifier (v.0.1.5) package.

Mutation analyses using low-density microarrays. Following their histopathological diagnosis, each tumor was tested for the presence of mutations of the KRAS, NRAS and BRAF genes. A multiplex allele-specific PCR-based assay was used for this purpose that assesses 44 mutations in KRAS codons 12, 13, 59, 61, 117 and 146 (G12A, G12C, G12D, G12R, G12S, G12V, G13D, A59E, A59G, A59T, Q61K (C > A), Q61K (C > AA), Q61L, Q61R, Q61H(A > T), Q61H(A > C), K117N(A > C), K117(A > T), A146P, A146V, and A146T), NRAS codons 12, 13, 59, 61, 117 and 146 (G12D, G12C, G12S, G12A, G12V, G13D, G13R, G13V, A59T, Q61K, Q61R, $\mathrm{Q} 61 \mathrm{~L}, \mathrm{Q} 61 \mathrm{H}(\mathrm{A}>\mathrm{C}), \mathrm{Q} 61 \mathrm{H}(\mathrm{A}>\mathrm{T}), \mathrm{K} 117 \mathrm{~N}(\mathrm{G}>\mathrm{C}), \mathrm{K} 117 \mathrm{~N}(\mathrm{G}>\mathrm{T}), \mathrm{A} 146 \mathrm{~T}$ and A146V) and BRAF codon 600 (V600E(T > A), V600E(G > AA), V600D, V600K and V600R). 51 assays were carried out using the CLART ${ }^{\circledR}$ CMA.KRAS.BRAF and CLART ${ }^{\circledR}$ CMA.NRAS.iKRAS kits (Genómica SAU Technology, Madrid, Spain) following the manufacturer's instructions. These are based on PCR amplification and array hybridization, respectively, with a variety of probes.

External validation of the prognostic impact of EGFR gene expression levels and its correlation with CNA. External validation of EGFR gene expression levels found to be differentially expressed in our series between non-metastatic and metastatic tumors, was performed in a group of previously reported sCRC patients $(\mathrm{n}=32)$ from whom GEP and CNA files and clinical data (Affymetrix, CA) are publicly available at the GEO database with accession number GSE16125 (Fig. 5) ${ }^{72}$.

Statistical analyses. The mean, standard deviation (SD) and range of all continuous variables were calculated in SPSS v.22 (IBM Corp., Armonk, NY, USA); dichotomous variables were reported as frequencies and percentages. To evaluate the statistical significance of group differences, unpaired Student's t and Mann-Whitney $\mathrm{U}$ tests were used for normally and non-normally distributed continuous variables, respectively. For dichotomous variables, the X2 test was used. Overall survival (OS) curves were plotted according to the Kaplan-Meier method. Statistical significance of the differences between survival curves was determined with one-sided log-rank tests. Prognostic factors for OS were identified by multivariate stepwise Cox regression, using forward selection, considering only those variables that had shown a significant association with OS in univariate analyses. Statistical significance was concluded for values of $p$ (or, where appropriate, Pearson-corrected $p$ ) $<0.05$.

Received: 15 January 2019; Accepted: 26 February 2020;

Published online: 13 March 2020

\section{References}

1. Colorectal cancer Source: Globocan 2018 Number of new cases in 2018, both sexes, all ages, http://gco.iarc.fr/today (2018).

2. Parkin, D. M. Global cancer statistics in the year 2000. Lancet Oncol. 2, 533-43 (2001).

3. Sartore-Bianchi, A. et al. Epidermal growth factor receptor gene copy number and clinical outcome of metastatic colorectal cancer treated with panitumumab. J. Clin. Oncol. 25(22), 3238-45 (2007).

4. Golubnitschaja, O. \& Sridhar, K. C. Liver metastatic disease: new concepts and biomarker panels to improve individual outcomes. Clin. Exp. Metastasis 33(8), 743-55 (2016).

5. Eschrich, S. et al. Molecular staging for survival prediction of colorectal cancer patients. J. Clin. Oncol. 23(15), 3526-35 (2005).

6. González-González, M. et al. Prognostic Impact of $\operatorname{del}(17 \mathrm{p})$ and $\operatorname{del}(22 \mathrm{q})$ as Assessed by Interphase FISH in Sporadic Colorectal Carcinomas. PLoS One 7, e42683 (2012).

7. Ma, Y. S. et al. Proteogenomic characterization and comprehensive integrative genomic analysis of human colorectal cancer liver metastasis. Mol. Cancer 17(1), 139 (2018).

8. Sayagués, J. M. et al. Mapping of genetic abnormalities of primary tumours from metastatic CRC by high-resolution SNP arrays. PLoS One 6, e13752 (2010).

9. Gutiérrez, M. L. et al. Prognostic impact of a novel gene expression profile classifier for the discrimination between metastatic and non-metastatic primary colorectal cancer tumors. Oncotarget 8(64), 107685-700 (2017).

10. Bouchie, A. Coming soon: a global grid for cancer research. Nat. Biotechnol. 22(9), 1071-3 (2004).

11. Motameny, S., Wolters, S., Nürnberg, P. \& Schumacher, B. Next Generation Sequencing of miRNAs - Strategies, Resources and Methods. Genes. 1(1), 70-84 (2010).

12. Kaserer, K. et al. Staining patterns of p53 immunohistochemistry and their biological significance in colorectal cancer. J. Pathol. 190(4), 450-6 (2000).

13. Syngal, S. et al. Interpretation of genetic test results for hereditary nonpolyposis colorectal cancer: implications for clinical predisposition testing. JAMA 282(3), 247-53 (1999).

14. Maltzman, T. et al. Ki-ras proto-oncogene mutations in sporadic colorectal adenomas: relationship to histologic and clinical characteristics. Gastroenterology 121(2), 302-9 (2001).

15. Vrabie, C. D., Ceauşu, M., Petrescu, A., Waller, M. \& Dina, I. The usefulness of immunohistochemistry in sporadic colorectal cancer. Rom. J. Morphol. Embryol. 49(4), 525-35 (2008)

16. Jansson, A. \& Sun, X. F. Ki-67 expression in relation to clinicopathological variables and prognosis in colorectal adenocarcinomas. APMIS 105(9), 730-4 (1997).

17. Ahmed, N. Y., Ismail, A. T. \& Kareem, T. S. A clinicopathologic study of Ki-67 proliferation index in colorectal carcinoma. Saudi Med. J. 33(8), 841-5 (2012).

18. Valera, V. et al. Clinical significance of Ki-67 proliferation index in disease progression and prognosis of patients with resected colorectal carcinoma. Br. J. Surg. 92(8), 1002-7 (2005)

19. Liu, B.-W., Liu, Y., Liu, J.-R., Feng, Z.-X. \& Liu, T. M. Prognostic effect of p53 expression in patients with completely resected colorectal cancer. Tumor Biol. 35(10), 9893-6 (2014). 
20. Nasif, W. A. et al. Implications of CEA and p53 overexpression in the poor prognosis of colorectal cancer. Med. Oncol. 23(2), 237-44 (2006).

21. Pyo, J. S., Kang, G. \& Park, K. Clinicopathological Significance and Diagnostic Accuracy of HER2 Immunohistochemistry in Colorectal Cancer: A Meta-Analysis. Int. J. Biol. Markers 31(4), 389-94 (2016).

22. Toon, C. W. et al. Immunohistochemistry for Myc Predicts Survival in Colorectal Cancer. PLoS One 9, e87456 (2014).

23. Qian, L.-Y., Li, P., Li, X.-R., Chen, D.-J. \& Zhu, S.-H. Multivariate analysis of molecular indicators for postoperative liver metastasis in colorectal cancer cases. Asian Pac. J. Cancer Prev. 13(8), 3967-71 (2012).

24. Li, N. et al. Expression of p53, Ki-67 and c-Myc proteins is predictive of the surgical molecular margin in colorectal carcinoma. Pathol. Oncol. Res. 17(3), 479-87 (2011)

25. Lee, K. S. et al. Favorable prognosis in colorectal cancer patients with co-expression of c-MYC and B-catenin. BMC Cancer 16(1), 730 (2016).

26. Benedix, F. et al. Comparison of 17,641 Patients With Right- and Left-Sided Colon Cancer: Differences in Epidemiology, Perioperative Course, Histology, and Survival. Dis. Colon. Rectum 53(1), 57-64 (2010).

27. Boland, C. R. \& Goel, A. Microsatellite Instability in Colorectal Cancer. Gastroenterology 138(6), 2073-2087 (2010).

28. Kloor, M., Staffa, L., Ahadova, A. \& von Knebel Doeberitz, M. Clinical significance of microsatellite instability in colorectal cancer. Langenbeck's Arch. Surg. 99(5), 23-31 (2014).

29. Alvarado-Bachmann, R. et al. The incidence of mismatch repair gene defects in colorectal liver metastases. Mol. Med. Rep. 10(2), 1003-6 (2014).

30. Kim, C. G. et al. Effects of microsatellite instability on recurrence patterns and outcomes in colorectal cancers. Br. J. Cancer 115(1), 25-33 (2016).

31. Setaffy, L. \& Langner, C. Microsatellite instability in colorectal cancer: clinicopathological significance. Pol. J. Pathol. 66(3), 203-18 (2015).

32. Saridaki, Z., Souglakos, J. \& Georgoulias, V. Prognostic and predictive significance of MSI in stages II/III colon cancer. World J. Gastroenterol. 20(22), 6809 (2014).

33. Guidoboni, M. et al. Microsatellite instability and high content of activated cytotoxic lymphocytes identify colon cancer patients with a favorable prognosis. Am. J. Pathol. 159(1), 297-304 (2001).

34. Michael-Robinson, J. M. et al. Tumour infiltrating lymphocytes and apoptosis are independent features in colorectal cancer stratified according to microsatellite instability status. Gut 48(3), 360-6 (2001).

35. Michael-Robinson, J. M. et al. Proliferation, apoptosis, and survival in high-level microsatellite instability sporadic colorectal cancer. Clin. Cancer Res. 7(8), 2347-56 (2001).

36. Compton, C. C. et al. Prognostic factors in colorectal cancer. College of American Pathologists Consensus Statement 1999. Arch. Pathol. Lab. Med. 124(7), 979-94 (2000).

37. Wang, J. Y. et al. Prognostic significance of pre- and postoperative serum carcinoembryonic antigen levels in patients with colorectal cancer. Eur. Surg. Res. 39(4), 245-50 (2007).

38. Ordoñez, C., Screaton, R. A., Ilantzis, C. \& Stanners, C. P. Human carcinoembryonic antigen functions as a general inhibitor of anoikis. Cancer Res. 60(13), 3419-24 (2000).

39. Bajenova, O. V. et al. Heterogeneous RNA-binding protein M4 is a receptor for carcinoembryonic antigen in Kupffer cells. J. Biol. Chem. 276(33), 31067-73 (2001).

40. Thomas, P., Forse, R. A. \& Bajenova, O. Carcinoembryonic antigen (CEA) and its receptor hnRNP M are mediators of metastasis and the inflammatory response in the liver. Clin. Exp. Metastasis 28(8), 923-32 (2011).

41. Kammerer, R. \& von Kleist, S. CEA expression of colorectal adenocarcinomas is correlated with their resistance against LAK-cell lysis. Int. J. cancer 57(3), 341-7 (1994).

42. Rego, R. L. et al. Prognostic effect of activated EGFR expression in human colon carcinomas: comparison with EGFR status. Br. J. Cancer 102(1), 165-72 (2010)

43. Spano, J. P. et al. Impact of EGFR expression on colorectal cancer patient prognosis and survival. Ann. Oncol. 16(9), 102-8 (2005).

44. Goos, J. A. C. M. et al. Epidermal growth factor receptor (EGFR) and prostaglandin-endoperoxide synthase 2 (PTGS2) are prognostic biomarkers for patients with resected colorectal cancer liver metastases. Br. J. Cancer 11 1(4), 749-55 (2014).

45. Goldstein, N. S. \& Armin, M. Epidermal growth factor receptor immunohistochemical reactivity in patients with American Joint Committee on Cancer Stage IV colon adenocarcinoma: implications for a standardized scoring system. Cancer 92(5), 1331-46 (2001).

46. Karameris, A. et al. Expression of epidermal growth factor (EGF) and epidermal growth factor receptor (EGFR) in gastric and colorectal carcinomas. An immunohistological study of 63 cases. Pathol. Res. Pract. 189(2), 133-7 (1993).

47. Radinsky, R. et al. Level and function of epidermal growth factor receptor predict the metastatic potential of human colon carcinoma cells. Clin. Cancer Res. 1(1), 19-31 (1995).

48. Du, P. et al. Hierarchical investigating the predictive value of p53, COX2, EGFR, nm23 in the post-operative patients with colorectal carcinoma. Oncotarget 8(1), 954-66 (2017).

49. Galizia, G. et al. Prognostic significance of epidermal growth factor receptor expression in colon cancer patients undergoing curative surgery. Ann. Surg. Oncol. 13(6), 823-35 (2006).

50. Tsai, W.-C. et al. Discordance between EGFR expression and clinicopathologic parameters of colorectal adenocarcinoma in Taiwan. Chin. J. Physiol. 55(5), 352-60 (2012).

51. Hemmings, C., Broomfield, A., Bean, E., Whitehead, M. \& Yip, D. Immunohistochemical expression of EGFR in colorectal carcinoma correlates with high but not low level gene amplification, as demonstrated by CISH. Pathol. 41 (6), 356-60 (2009).

52. Moroni, M. et al. Gene copy number for epidermal growth factor receptor (EGFR) and clinical response to antiEGFR treatment in colorectal cancer: a cohort study. Lancet Oncol. 6(5), 279-86 (2005).

53. Cappuzzo, F. et al. EGFR FISH assay predicts for response to cetuximab in chemotherapy refractory colorectal cancer patients. Ann. Oncol. 19(4), 717-23 (2008).

54. Shen, W.-D., Chen, H.-L. \& Liu, P.-F. EGFR gene copy number as a predictive biomarker for resistance to anti-EGFR monoclonal antibodies in metastatic colorectal cancer treatment: a meta-analysis. Chin. J. Cancer Res. 26(1), 59-71 (2014).

55. Khan, S. A., Zeng, Z., Shia, J. \& Paty, P. B. EGFR Gene Amplification and KRAS Mutation Predict Response to Combination Targeted Therapy in Metastatic Colorectal Cancer. Pathol. Oncol. Res. 23(3), 673-7 (2017)

56. Niu, C. S., Yang, Y. \& Cheng, C.-D. MiR-134 regulates the proliferation and invasion of glioblastoma cells by reducing Nanog expression. Int. J. Oncol. 42(5), 1533-40 (2013).

57. Zhang, X. et al. MiR-134 functions as a regulator of cell proliferation, apoptosis, and migration involving lung septation. Vitro Cell Dev. Biol. Anim. 48(2), 131-6 (2012).

58. Li, J. et al. miR-134 inhibits epithelial to mesenchymal transition by targeting FOXM1 in non-small cell lung cancer cells. FEBS Lett. 586(20), 3761-5 (2012).

59. Liu, Y. et al. miR-134 functions as a tumor suppressor in cell proliferation and epithelial-to-mesenchymal Transition by targeting KRAS in renal cell carcinoma cells. DNA Cell Biol. 34(6), 429-36 (2015).

60. Qin, Q., Wei, F., Zhang, J., Wang, X. \& Li, B. miR-134 inhibits non-small cell lung cancer growth by targeting the epidermal growth factor receptor. J. Cell Mol. Med. 20(10), 1974-83 (2016). 
61. El-Daly, S. M., Abba, M. L., Patil, N. \& Allgayer, H. miRs-134 and -370 function as tumor suppressors in colorectal cancer by independently suppressing EGFR and PI3K signalling. Sci. Rep. 6(2), 24720 (2016).

62. Bjaanaes, M. M. et al. Unique microRNA-profiles in EGFR-mutated lung adenocarcinomas. Int. J. cancer 135(8), 1812-21 (2014).

63. Egner, J. R. AJCC Cancer Staging Manual. JAMA 304, 1726 (2010).

64. Sousa, W. A. T., Rodrigues, L. V., Silva, R. G. \& Vieira, F. L. Immunohistochemical evaluation of $\mathrm{p} 53$ and Ki-67 proteins in colorectal adenomas. Arq. Gastroenterol. 49(1), 35-40 (2012).

65. González-González, M. et al. Identification of a characteristic copy number alteration profile by high-resolution single nucleotide polymorphism arrays associated with metastatic sporadic colorectal cancer. Cancer 120(13), 1948-59 (2014).

66. Muñoz-Bellvis, L. et al. Unique genetic profile of sporadic colorectal cancer liver metastasis versus primary tumors as defined by high-density single-nucleotide polymorphism arrays. Mod. Pathol. 25(4), 590-601 (2012).

67. Sayagués, J. M. et al. Genomic characterization of liver metastases from colorectal cancer patients. Oncotarget 7(45), 72908-22 (2016).

68. Saeed, A. I. et al. TM4: a free, open-source system for microarray data management and analysis. Biotechniques 34(2), 374-8 (2003).

69. Tusher, V. G., Tibshirani, R. \& Chu, G. Significance analysis of microarrays applied to the ionizing radiation response. Proc. Natl Acad. Sci. USA 98(9), 5116-21 (2001).

70. Dweep, H., Sticht, C., Pandey, P. \& Gretz, N. miRWalk-database: miRWalk-database: prediction of possible miRNA binding sites by "walking" the genes of three genomes. J. Biomed. Inf. 44(5), 839-47 (2011).

71. Xiao, F. et al. miRecords: an integrated resource for microRNA-target interactions. Nucleic Acids Res. 37, D105-10 (2009).

72. Reid, J. F. et al. Integrative approach for prioritizing cancer genes in sporadic colon cancer. Genes. Chromosomes Cancer 48(11), 953-62 (2009).

\section{Acknowledgements}

This work has been partially supported by grants from the Gerencia Regional de Salud de Castilla y León, Valladolid, Spain (GRS2051/A/19), CIBERONC from the ISCIII (CB16/12/00400) and the Fundación Memoria de Don Samuel Solórzano Barruso, Salamanca, Spain

\section{Author contributions}

Conception and design: S.C., J.M.S. and M.A. Development of method: L.A.C., R.G., A.R., M.G., J.A.A. and J.G. Acquisition of data: O.B., Analysis and interpretation of data: S.C., J.M.S. and M.A., Writing, review, and/or revision of the manuscript: S.C., J.M.S. and M.A. Study supervision: L.M.B.

\section{Competing interests}

The authors declare no competing interests.

\section{Additional information}

Supplementary information is available for this paper at https://doi.org/10.1038/s41598-020-61688-7.

Correspondence and requests for materials should be addressed to J.M.S. or M.A.

Reprints and permissions information is available at www.nature.com/reprints.

Publisher's note Springer Nature remains neutral with regard to jurisdictional claims in published maps and institutional affiliations.

(c) (i) Open Access This article is licensed under a Creative Commons Attribution 4.0 International License, which permits use, sharing, adaptation, distribution and reproduction in any medium or format, as long as you give appropriate credit to the original author(s) and the source, provide a link to the Creative Commons license, and indicate if changes were made. The images or other third party material in this article are included in the article's Creative Commons license, unless indicated otherwise in a credit line to the material. If material is not included in the article's Creative Commons license and your intended use is not permitted by statutory regulation or exceeds the permitted use, you will need to obtain permission directly from the copyright holder. To view a copy of this license, visit http://creativecommons.org/licenses/by/4.0/.

(C) The Author(s) 2020 